\title{
Predictability of the Atlantic Overturning Circulation and Associated Surface Patterns in Two CCSM3 Climate Change Ensemble Experiments
}

\author{
Haiyan Teng, Grant Branstator, and Gerald A. Meehl \\ National Center for Atmospheric Research, * Boulder, Colorado
}

(Manuscript received 15 November 2010, in final form 4 May 2011)

\begin{abstract}
Predictability of the Atlantic meridional overturning circulation (AMOC) and associated oceanic and atmospheric fields on decadal time scales in the Community Climate System Model, version 3 (CCSM3) at T42 resolution is quantified with a 700-yr control run and two 40-member "perfect model" climate change experiments. After taking into account both the mean and spread about the mean of the forecast distributions and allowing for the possibility of time-evolving modes, the natural variability of the AMOC is found to be predictable for about a decade; beyond that range the forced predictability resulting from greenhouse gas forcing becomes dominant. The upper 500-m temperature in the North Atlantic is even more predictable than the AMOC by several years. This predictability is associated with subsurface and sea surface temperature (SST) anomalies that propagate in an anticlockwise direction along the subpolar gyre and tend to be prominent during the $10 \mathrm{yr}$ following peaks in the amplitude of AMOC anomalies. Predictability in the North Atlantic SST mainly resides in the ensemble mean signals after three to four forecast years. Analysis suggests that in the CCSM3 the subpolar gyre SST anomalies associated with the AMOC variability can influence the atmosphere and produce surface climate predictability that goes beyond the ENSO time scale. However, the resulting initial-value predictability in the atmosphere is very weak.
\end{abstract}

\section{Introduction}

In this paper we explore the decadal time-scale predictability of the Atlantic meridional overturning circulation (AMOC) and associated oceanic and atmospheric fields as they are represented in the T42 version of the Community Climate System Model version 3 (CCSM3) (W. D. Collins et al. 2006). Characterization and quantification of decadal predictability is of special interest because many climate modeling groups from around the world are producing decadal hindcasts and predictions as part of the Coupled Model Intercomparison Project phase 5 (CMIP5). Those simulations will be evaluated as part of the Fifth Assessment Report of the Intergovernmental Panel on Climate Change (IPCC) (Taylor et al. 2011). The approach that they are using is to run fully coupled climate models with an initialized ocean

\footnotetext{
* The National Center for Atmospheric Research is sponsored by the National Science Foundation.

Corresponding author address: Haiyan Teng, National Center for Atmospheric Research, P.O. Box 3000, Boulder, CO 80307.

E-mail: hteng@ucar.edu
}

and estimated anthropogenic and natural forcing. The hypothesis is that climate models will be able to take advantage of information in the initial condition to predict the evolution of the large-scale patterns of sea surface temperature (SST) in the coming decades, and, furthermore, it is hypothesized that the forecast SSTs will bring predictive skill in atmospheric conditions over land.

In contrast to weather prediction and seasonal prediction based primarily on ENSO, decadal prediction is still in its infancy. It is assumed that the oceans are the most predictable component of the climate system on decadal time scales, but there is no clear understanding of what their predictability limits are, whether the predictability that exists in the oceans carries over to surface atmospheric conditions and what phenomena and processes would produce long predictability (Meehl et al. 2009; Hurrell et al. 2009; Solomon et al. 2011). Unfortunately, there is no effective means of comprehensively determining these properties for nature, but they can be estimated for models. Measuring the predictability of a model is useful for two reasons. A model's initial-value predictability limit is an upper bound on the range at which specifying a particular initial condition has the potential to add skill to forecasts made with that model 
and, to the extent that a model bears a similarity to nature, its predictability limit provides an estimate of the limits inherent in nature.

Our study, like others, focuses on predictability related to the AMOC because it is assumed to be an especially predictable component of the ocean circulation (M. Collins et al. 2006) and because it has the potential to influence fluctuations in climate over Europe, Asia, and North America (Delworth et al. 2008). Among the ocean initial-value predictability studies that began with Griffies and Bryan (1997), many have found that the AMOC has predictability on the decadal time scale (Collins 2002; Collins and Sinha 2003; Pohlmann et al. 2004; M. Collins et al. 2006; Msadek et al. 2010; Hurrell et al. 2009). However, there is still considerable disagreement regarding the basic characteristics of the AMOC including its intrinsic time scale of variability, the physical mechanisms for its natural variability, and what role it plays in the regional and global climate of the atmosphere.

AMOC characteristics vary from one model to another, and various mechanisms have been proposed to explain these behaviors. The proposed mechanisms are generally categorized (reviewed by Saravanan et al. 2000; Latif et al. 2006) based on whether periodic behavior crucially depends on atmospheric feedbacks to the ocean. Here we are particularly interested in several distinctions in the CCSM3. One is whether ocean decadal variability receives much of its driving from the atmosphere (e.g., Delworth et al. 1993; Delworth and Greatbatch 2000; Dai et al. 2005; Dong and Sutton 2005; Jungclaus et al. 2005; Park and Latif 2005; Timmermann et al. 1998). Intrinsic atmospheric variability has no preferred time scales longer than a few weeks, so it should decrease AMOC predictability, though it does not necessarily restrict oceanic predictability to a few weeks. Another distinction with which we are concerned is whether predictable oceanic signals influence the atmosphere, for ultimately it is this impact that will produce the atmospheric predictability that could benefit society (Delworth et al. 2008; Sutton and Hodson 2005, 2007; Msadek and Frankignoul 2009; Zhang 2008). If the ocean does produce an impact on the atmosphere, this also opens the possibility of a positive feedback loop that could enhance ocean predictability. A third distinction is whether there are recurring, long-lasting modes of oceanic variability and whether they are propagating or standing (Saravanan and McWilliams 1998; Saravanan et al. 2000). The existence of such modes and their structural characteristics will influence how we measure and isolate decadal predictability.

If there is significant AMOC predictability, its practical consequences will be greatly enhanced if it leads to significant decadal predictability in the overlying atmosphere.
Some modeling studies suggest the possibility that the North Atlantic SST mode of variability known as the Atlantic multidecadal oscillation (AMO) results from fluctuations of the AMOC (Knight et al. 2006; Delworth and Mann 2000). The AMO, which consists of a pattern of like-signed anomalies throughout the North Atlantic basin, is associated with variations in air temperature and rainfall in North America and Europe (Sutton and Hodson 2005, 2007; Enfield et al. 2001), as well as a number of key climate phenomena including Sahelian rainfall and Atlantic hurricane activity (Landsea et al. 1999; Knight et al. 2006; Zhang and Delworth 2006; Lu and Delworth 2005). However, the physical mechanism for the AMO-AMOC linkage is not understood in either observations or models, and which mechanism the atmosphere uses to react to midlatitude SST anomalies is controversial (Kushnir et al. 2002).

Initializing with a particular state is not the only means of producing forecasts with useful information. Changes in system forcing can also contribute to predictability (Lorenz 1963). With increasing greenhouse gas (GHG) concentrations, global warming tends to weaken the AMOC by warming the upper North Atlantic Ocean and enhancing freshwater flux, so AMOC predictability can have a contribution from this second mechanism. Recently, Branstator and Teng (2010, hereafter BT2010) used several CCSM3 large ensemble experiments with perturbed atmospheric initial conditions to quantify initial-value predictability and predictability of the forced response in upper-ocean heat content. They found that, for the North Atlantic, initial-value predictability is lost after perhaps 13 years, but GHG effects become the dominant source of predictability after only about 9 years. While BT2010 focused on quantification of initialvalue and forced predictability on the basin scale in upperocean heat content of the North Pacific and the North Atlantic, here we are interested in discovering whether the common assumption that AMOC predictability is greater than the predictability of near-surface fields is valid for the CCSM3 and what the relative importance of initial value and forced predictability is for AMOC and related fields.

The aim of this study is to document the following four aspects of AMOC behavior in the CCSM3: What is the predictability of the AMOC? In the CCSM3, AMOC has been shown to exhibit prominent 20 -yr variability that is likely driven by the North Atlantic Oscillation (NAO) (Hurrell 1995; Marshall et al. 2001) via its effect on convection in the deep-water formation region in the Labrador Sea (Danabasoglu 2008; Kwon and Frankignoul 2011). So, it is of interest to see how much decadal AMOC predictability can exist despite significant atmospheric forcing. Is there associated predictability in near-surface 
oceanic fields? Do these signals lead to detectable, predictable atmospheric signals? How important are predictable signals associated with AMOC natural variability compared to the forced response?

To address these questions we briefly describe the CCSM3 and our numerical experiments and analysis methods in section 2; report on the natural variability of the AMOC and its linkage with the North Atlantic subsurface and surface conditions and with atmospheric fields in section 3; quantify the predictability of the AMOC, the North Atlantic subsurface temperature, and SST in section 4; investigate atmospheric surface climate predictability in section 5; and summarize our results and discuss their implications in section 6 .

\section{Model, experiments, and analysis methods}

We only provide a brief description of our model, experiments, and analysis procedures, as the underlying assumptions and detailed analysis methods have been described in BT2010.

\section{a. Model and experiments}

The CCSM3 is a fully coupled model that has four components: atmosphere, ocean, land, and sea ice (W. D. Collins et al. 2006). In this study we use a version that has a T42 atmosphere and nominal $1^{\circ}$ ocean for both a 1000-yr present-day control experiment and "perfect model" ensemble experiments. Aspects of the climate in the CCSM3 are described in more detail in Large and Danabasoglu (2006), Bryan et al. (2006), and Alexander et al. (2006). Although the model climatology is generally realistic, some significant cold and fresh biases are found in the North Atlantic (Large and Danabasoglu 2006). Both the climatology and variability of the AMOC have resolution dependency in the CCSM3 (Bryan et al. 2006). In the last 700 years of the T42 present-day control run, the climatological mean and interannual standard deviation of the maximum Atlantic meridional overturning streamfunction below $500 \mathrm{~m}$ are about $19.3 \mathrm{~Sv}$ and $1.0 \mathrm{~Sv}\left(\mathrm{~Sv} \equiv 10^{6} \mathrm{~m}^{3} \mathrm{~s}^{-1}\right)$, respectively. It shows a prominent 20-yr frequency peak (Danabasoglu 2008).

Much of our analysis concerns two large ensemble experiments that differ only in the anthropogenic forcing: one is forced by the Special Report on Emissions Scenarios (SRES) A1B scenario and the other has the forcing fixed at the year 2000 level (Meehl et al. 2006). Both ensembles are integrated from year 2000 to 2061. We refer to them as the "A1B" and "Commitment" ensembles, respectively. The statistics of the Commitment scenario are different from those of the standard control run because the thermal inertia of the deep ocean and other components of the climate system can cause a delayed response to changes in external forcings (Meehl et al. 2005). All realizations from the two ensembles have identical ocean, land, and sea ice initial conditions, which are taken from 1 January 2000 of a CCSM3 twentieth-century run. The 40 atmospheric initial states come from different days in December 1999 and January 2000 from the same historical run. This experimental design is mainly intended to address the question of how long the dominant oceanic patterns can maintain predictability given that they are subjected to the day-to-day variability of weather noise and the ocean is chaotic.

Since the predictability properties of a climate system can depend on the initial state, analyzing one ocean initial state is one of the limitations to this study. To assess predictability associated with other ocean, land, and sea ice initial conditions, three additional A1B 40-member ensemble experiments are used; they are branched from three different realizations of the A1B ensemble at year 2008, 2008, and 2010, and are referred to as A1B (II), A1B (III), and A1B (IV), respectively. Each of their ocean initial states features a strong projection onto the leading basin EOF pattern either in the North Pacific (Teng and Branstator 2011, hereafter TB2011) or in the North Atlantic. Unlike the primary A1B ensemble, in these three supplementary experiments each realization has the same initial state for all four model components but each realization is distinct because we perturbed the solar constant value by at most $0.000002 \%$. This is dynamically equivalent to having the 40 initial conditions be very slightly different from each other.

We employ the T42 1000-yr present-day control run for learning about the model intrinsic variability and baseline distribution, and for assessing statistical significance. Only the last 700 years are analyzed to avoid the period when spinup is prominent. Throughout the study, we use annual means of the ocean variables, including the Atlantic meridional overturning streamfunction, upper-500-m temperature ${ }^{1}$ and SST, and DecemberFebruary (DJF) and July-September (JAS) seasonal means of atmosphere variables.

\section{b. Initial-value predictability and forced predictability}

Predictability associated with a particular initial condition usually deteriorates with time. As mentioned earlier, when a climate system reacts to changing external forcing-for example, increasing greenhouse gas

\footnotetext{
${ }^{1}$ BT2010 used the upper 300-m temperature to quantify initialvalue predictability in the global ocean. Here we expand the depth averaging to $500 \mathrm{~m}$ because of the deeper mixing layer in the North Atlantic, and we find the predictability limit is quite similar to that of the upper $300-\mathrm{m}$ temperature.
} 
a) schematic
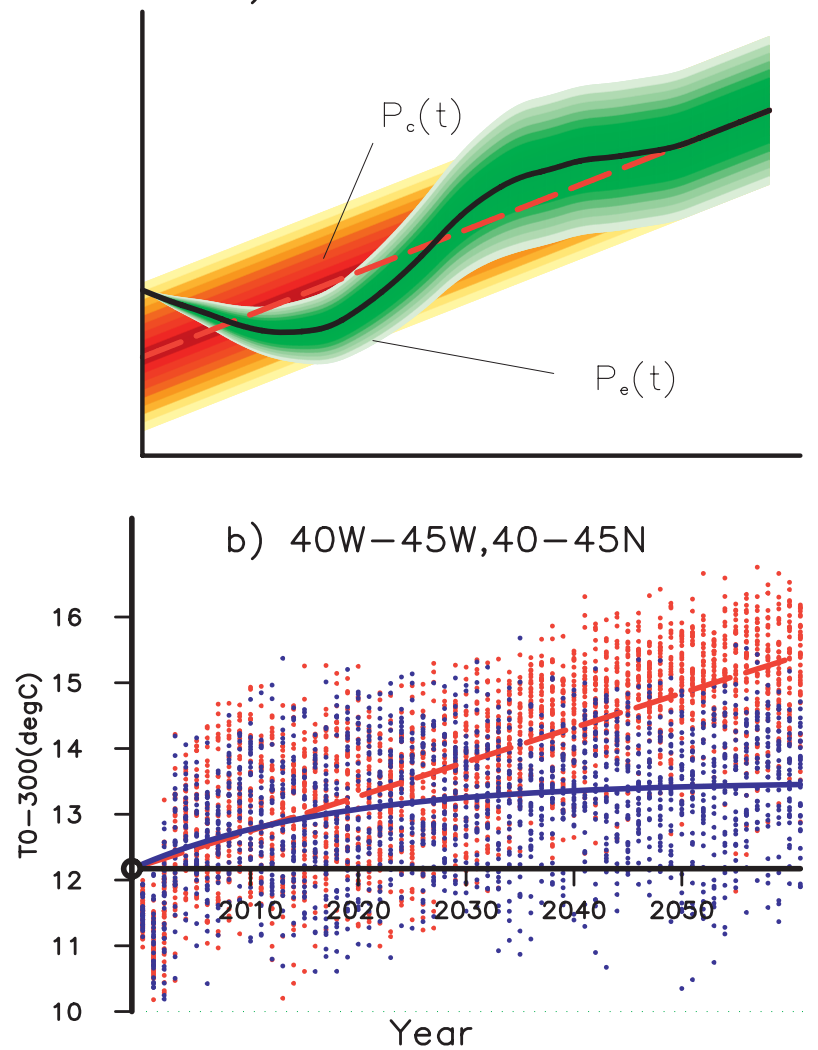

FIG. 1. (a) Schematic diagram of time-evolving distributions under changing external forcing; the abscissa is time. The yellow/ red shading represents the climatological distribution $\left[P_{c}(t)\right]$. It is independent of any particular initial state. $P_{e}(t)$ (green shading) is an ensemble of predicted states evolving from a specific tight cluster of initial conditions. $P_{e}(t)$ eventually converges with $P_{c}(t)$ as the influence of the particular initial conditions is lost. Red dashed and black solid lines represent the time-evolving means of the two distributions. (b) Scatterplot of annual mean upper-300-m ocean temperature at $40^{\circ}-45^{\circ} \mathrm{N}, 40^{\circ}-45^{\circ} \mathrm{W}$ in the $\mathrm{A} 1 \mathrm{~B}$ (red) and Commitment (blue) ensembles. Red dashed and blue solid lines denote the two ensemble time-evolving climatological mean estimated via (1) and (2), respectively. Black open circle at the origin denotes the year 1999 climatological mean, estimated by extrapolating the A1B linear trend [Eq. (1)] (adapted from BT2010).

concentrations-the forcing induces so-called predictability of the second kind (Lorenz 1963), which grows with time. As illustrated in BT2010's Fig. 1a (reproduced here as Fig. 1a for clarity), to quantify and compare these two types of predictability it is helpful to think of two time-evolving distributions. One is the distribution of predicted states $P_{e}(t)$ resulting from marching from a specific initial distribution of states $P_{e}(0)$ forward in time. The second distribution $P_{c}(t)$ represents the time-evolving climatological reaction to the forcing and is independent of any particular initial state. Eventually $P_{e}(t)$ converges to $P_{c}(t)$, indicating that the initial-value predictability is lost. At any given time, measures of "total predictability" deal with comparing $P_{e}(t)$ with $P_{c}(0)$. It has two components: "initial value predictability," which represents the difference between $P_{e}(t)$ and $P_{c}(t)$, and "forced predictability," which can be measured by comparing $P_{c}(t)$ with $P_{c}(0)$. These two components, which do not necessarily add up exactly to the "total predictability," provide a means of comparing the relative importance of the initial value and the external forcing.

We assume the predicted ensemble distributions, as well as distributions from the control that they are compared to, are well approximated by Gaussians. Two other assumptions that we employ to define $P_{c}(t)$ are that the covariance structure of the system climate does not change with forcing during the first 20 forecast years and the climate mean of $P_{c}(t)$ is well approximated by a linear and exponential function for the $\mathrm{A} 1 \mathrm{~B}$ and Commitment ensembles, respectively, once the influence of the initial condition is weak. As in BT2010, the functions that we have assumed are good approximations to the time-evolving climate mean [i.e., the means of $P_{c}(t)$ ] are the linear function

$$
\bar{T}_{\mathrm{A} 1 \mathrm{~B}}(t)=\bar{T}_{1999}+k(t-1999)
$$

for the A1B experiment and the exponential function

$$
\bar{T}_{\text {commit }}(t)=\bar{T}_{1999}+A\left(1-e^{-t / \tau}\right)
$$

for the Commitment experiment. In these expressions model year $t$ varies from 2000 to 2061. We have estimated constant $k$ by least squares fitting a line to A1B ensemble values during 2010-62. Ideally, $\bar{T}_{1999}$ would be estimated with an ensemble of twentieth-century runs. However, with only one realization available, we have instead extrapolated the fitted line in (1) to $t=1999$ to derive $\bar{T}_{1999}$. Next, we have inserted the resulting $\bar{T}_{1999}$ in (2) and calculated $\tau$ and $A$ by least squares fitting of Commitment values during 2010-61.

To provide an example of how we calculated climate means of $P_{c}(t)$ for the $\mathrm{A} 1 \mathrm{~B}$ and Commitment experiments, we again adapt a figure from BT2010 (our Fig. 1b). The red and blue dots in this figure correspond to layer mean temperatures in a North Atlantic box for each ensemble member for each year of the experiments, and the red and blue lines represent $\bar{T}_{\mathrm{A} 1 \mathrm{~B}}$ and $\bar{T}_{\text {commit }}$ as derived from (2). Note that measures of initial value predictability concern departures of the red and blue dots from the red and blue lines, respectively. We refer to these departures collectively as the "initial value components" of a forecast to distinguish them from the "raw" forecast states. When initial value predictability is lost, the mean of the initial value components is zero and 
the distribution about the mean matches the distribution of $P_{c}(t)$ about its mean. In Fig. 1b early in the forecasts the distribution of the initial value component is clearly distinguishable from the climatological distribution both because of the narrowness of its spread and the separation of the ensemble mean from the climate mean. The forced predictability can be measured by the departures of $\bar{T}_{\text {A1B }}(t)$ and $\bar{T}_{\text {commit }}(t)$ from $\bar{T}_{1999}$ because the spread contribution to the distribution difference is negligible under our first assumption.

\section{c. Relative entropy}

To measure the departure of a distribution $P_{x}$ [e.g., $\left.P_{e}(t)\right]$ from a baseline distribution $P_{b}$ [e.g., $P_{c}(t)$ ], we follow the same approach employed by BT2010 and use relative entropy. This measure, which has its foundation in information theory, was introduced to climate research by Kleeman (2002) and Majda et al. (2005). When, as in our study, $P_{x}$ and $P_{b}$ are assumed to be Gaussian with $n$ degrees of freedom, relative entropy can be calculated from

$$
\begin{aligned}
R= & \frac{1}{2} \log _{2}(e)\left[\ln \left(\frac{\operatorname{det}\left(\sigma_{b}^{2}\right)}{\operatorname{det}\left(\sigma_{x}^{2}\right)}\right)+\operatorname{trace}\left(\sigma_{x}^{2} / \sigma_{b}^{2}\right)\right. \\
& \left.+\left(\mu_{x}-\mu_{b}\right)^{\mathrm{T}}\left(\sigma_{b}^{2}\right)^{-1}\left(\mu_{x}-\mu_{b}\right)-n\right]
\end{aligned}
$$

where $\mu_{b}$ and $\mu_{x}$ stand for the mean state vectors in distributions $P_{b}$ and $P_{x}$, respectively, while $\sigma_{b}^{2}$ and $\sigma_{x}^{2}$ correspond to covariance matrices representing relationships between elements of state vectors in these same distributions. Note that we choose to use base 2 in (3) as was done in BT2010, while relative entropy in Kleeman (2002) and TB2011 is expressed in base $e$. This choice means that relative entropy values are given in terms of binary bits of information in the predicted states.

One feature of using this Gaussian approximation for $R$ is that it can be decomposed into contributions from the mean-namely, the third term in the brackets-and from the covariances, which are the rest of the terms. These are commonly referred to as the "signal" and the "dispersion" components, respectively (Kleeman 2002). ${ }^{2}$ Often only ensemble means are used when applying forecasts, so distinguishing the information in these two components is of interest.

Another merit of relative entropy is that it can be applied to multidimensional fields. Similar to BT2010, we have chosen to represent fields in terms of EOF bases

\footnotetext{
${ }^{2}$ Note, because we assume the covariance structure of $P_{c}(t)$ is time independent, only the signal contributes to forced predictability in our study.
}

calculated from the control run. We then project the predicted fields onto these bases to get the predicted vectors. Like BT2010, we truncate representations at 15 EOFs, which represent $94 \%, 88 \%$, and $86 \%$ of the total variance for the Atlantic meridional overturning streamfunction, the North Atlantic upper-500-m ocean temperature, and SST, respectively.

In our study, we have 700 samples from the control run to estimate the climatological distribution, but only 40 samples for predictions. The limited sample size of the prediction ensemble induces an error in the estimation of relative entropy. As a result, relative entropy asymptotes to a nonzero value for long forecast ranges when the predictability is lost. We estimate this value by calculating relative entropy from many samples of 40 randomly chosen states from the control run, and in some of our figures the 95th percentile of these values is plotted to indicate when predictability is lost.

\section{10-30-yr natural variability}

\section{a. Oceanic variability}

As mentioned in the introduction, earlier studies have shown that in CCSM3 the AMOC exhibits pronounced decadal variability with a significant peak in its power spectrum at about 20 years (Bryan et al. 2006; Danabasoglu 2008). If there is decadal predictability in the AMOC, it may be associated with this intrinsic feature. Therefore, we first focus on analyzing this prominent decadal mode and its associations with surface climate, as it is manifested in the control integration.

The spatial pattern of the leading two EOFs of the detrended annual mean Atlantic meridional overturning streamfunction and the corresponding power spectra are shown in Fig. 2. EOF1 has a single-cell pattern covering the entire Atlantic Ocean south of $60^{\circ} \mathrm{N},{ }^{3}$ indicating strengthening/weakening and deepening/shallowing of the mean AMOC streamfunction. It accounts for $33 \%$ of the total variance. The time series of the corresponding first principal component (PC1) has a strong correlation (with a simultaneous correlation coefficient value of 0.77 ) with the maximum overturning streamfunction between $0^{\circ}$ and $60^{\circ} \mathrm{N}$ and 500 and $5000 \mathrm{~m}$ (not shown), which has been frequently used as an index to depict the strength of the AMOC (Delworth et al. 1993). The significant peak in its power spectrum, noted in other studies, is evident in Fig. 2. EOF2 has received less attention in previous studies. In the CCSM3 it explains $18 \%$ of the interannual variance and is characterized by a dipole pattern with

\footnotetext{
${ }^{3}$ The results of this study are not affected when we expand the AMOC EOF domain to $75^{\circ} \mathrm{N}$.
} 

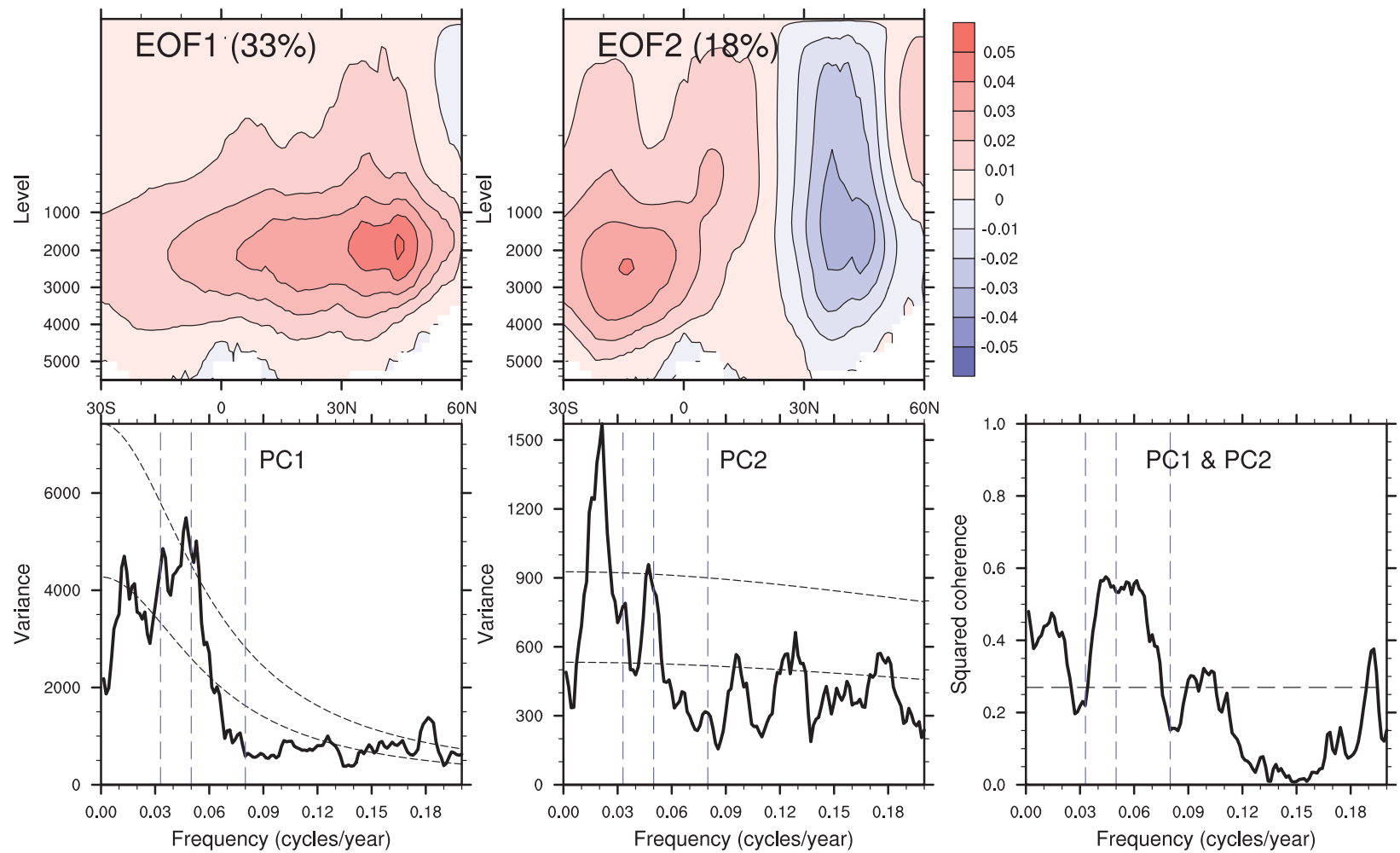

FIG. 2. Leading two EOFs of detrended annual mean Atlantic meridional overturning streamfunction (top) from the 700-yr control run and power spectra for the principal component (PC) of (bottom left) EOF1, (bottom middle) EOF2, and (bottom right) coherence between the leading two PCs. the two black dashed lines superimposed on the power spectra are the first-order autoregressive model (AR1) spectra and 99\% significance level based on the 1-yr lag autocorrelations of the time series; the horizontal dashed line superimposed on the squared coherence indicates the $99 \%$ significance level.

opposing meridional circulations south and north of $25^{\circ} \mathrm{N}$. The power spectrum of the PC2 time series has two prominent peaks at 50 and $20 \mathrm{yr}$. The two EOFs have strong coherence in the 10-30-yr frequency band (Fig. 2, bottom right), suggesting the two patterns correspond to a time-dependent physical mode.

If there is a prominent time-evolving mode in the meridional overturning streamfunction whose variability is approximately sinusoidal, the variability can be described by a pair of patterns that should be captured by complex EOF (CEOF) analysis (von Storch and Zwiers 1999). When we apply CEOF analysis to the 10 30 -yr filtered overturning streamfunction, we find that the real and imaginary parts of the first CEOF (Fig. 3, bottom left two panels) resemble EOF1 and EOF2 of the same filtered data (Fig. 3, upper left two panels). In Fig. 3, the complex eigenvector has been rotated to make the real and imaginary parts orthogonal. The two real EOFs explain $62 \%$ and $11 \%$ of the variance in this band. The two patterns largely agree with the leading two EOFs in the unfiltered data, except that the southern meridional circulation cell penetrates farther into the Northern Hemisphere in EOF2 of the filtered data.
EOF1 is much more dominant than EOF2 in terms of variance explained in the 10-30-yr frequency band, suggesting that the $10-30-y r$ variability of the AMOC is to first order a standing mode.

Though EOF1 is dominant, further analysis suggests that it is informative to take into account its relationship to EOF2 implied by their pairing in the CEOF analysis. Lag correlations between the time series of $10-30-y r$ filtered projections onto the leading two EOFs (or the CEOF1 real and imaginary parts) seem to indicate a perfect 20-yr oscillation (red curves in Fig. 3, right panels) with PC2 lagging PC1 by 4 yr and negative PC2 leading PC1 by 4 yr. But, additional calculations suggest to us that the 20 -yr variability is not an oscillation. For example, when we project unfiltered meridional overturning streamfunction anomalies onto the leading EOF and CEOF1 patterns in Fig. 3 and recalculate the lag correlation coefficients, the blue curves in the Fig. 3 right panels are produced. Although EOF1 still tends to evolve to EOF2 after $4 \mathrm{yr}$ in the unfiltered data, there is no significant lag correlation when negative EOF2 leads EOF1. Also, the placement of the frequency peak is sometimes offset from $20 \mathrm{yr}$ in different segments of the control run. 

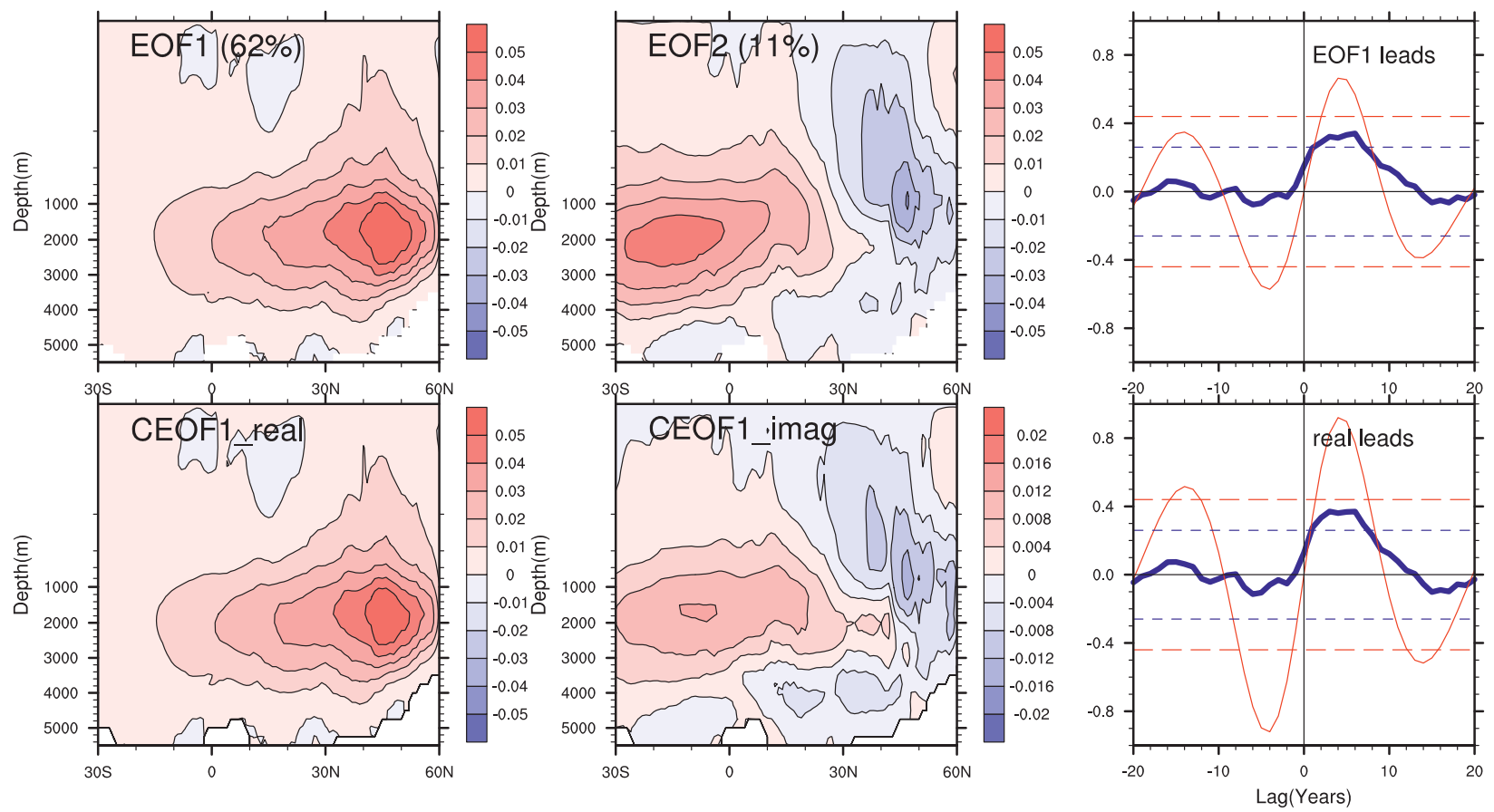

FIG. 3. (top) EOF1 and EOF2 and (bottom) real and imaginary parts of complex EOF1 (CEOF1) of the 10-30-yr filtered Atlantic meridional overturning streamfunction from the 700-yr control run. The red solid line plotted in the right-hand panels is the lag correlation between PC1 and PC2 and between time series of the real and imaginary parts of CEOF1, with the red horizontal dashed line indicating the $95 \%$ significance level and the blue solid and dashed lines the lag correlation between the time series of the unfiltered data and the corresponding $95 \%$ significance level.

The 10-30-yr variability of the AMOC is closely connected with the horizontal circulation and temperature anomalies. This connection is apparent in Fig. 4, where we have regressed simultaneous and lagged values of annual mean SST, mean upper 500-m temperature, and barotropic streamfunction (BSF) against unfiltered AMOC PC1. At lag-0 year, accompanying the enhanced meridional overturning streamfunction of positive AMOC EOF1 are BSF anomalies that represent a strengthening of both subtropical and subpolar gyres. Both subsurface temperature and SST have a north-south dipole pattern, with cooling in the subpolar gyre region and warming of the Gulf Stream extension. Thereafter, as the single cell of AMOC EOF1 decays, growth of EOF2 at lag-4 and lag-6 years becomes apparent. Most interestingly, there are coherent warm SST and subsurface temperature anomalies propagating anticlockwise from the Gulf Stream extension region toward the region southeast of Greenland. The location of the warm anomalies coincides with that of the positive anomalies of the BSF. Prominent propagation of SST anomalies along the North Atlantic Current are also seen in nature, except that the observed propagating signals have higher frequency (with a 12-14-yr period) and stronger amplitude $\left(0.5^{\circ}-1^{\circ} \mathrm{C}\right)$ (Sutton and Allen 1997$)$.
The SST anomalies associated with the AMOC variability are mostly confined to the North Atlantic subpolar gyre region, which is different from the AMO pattern (Sutton and Hodson 2005) often found to be associated with AMOC variability in other studies. The AMO features basinwide anomalies in the North Atlantic and has a much lower frequency. Following the AMO definition of Sutton and Hodson, we calculate the AMO index in the 700-yr control run by averaging the detrended SST over the entire North Atlantic $\left(0^{\circ}-60^{\circ} \mathrm{N}, 75^{\circ}-7.5^{\circ} \mathrm{W}\right)$. The correlation coefficient between the AMO index and AMOC PC1 is insignificant (Danabasoglu 2008). Therefore, the AMOC-AMO linkage in the CCSM3 is very different from the linkage in another prominent climate model—namely, the Geophysical Fluid Dynamics Laboratory Climate Model version 2.1 (CM2.1), in which a close linkage is found (Zhang 2008).

The anticlockwise propagation of the subsurface temperature anomalies in the subpolar region in Fig. 4 represents the most prominent mode in the entire North Atlantic subsurface temperature variability. Its prominence can be seen when one examines the leading two EOFs of the upper 500-m temperature (Fig. 5, bottom left two panels), which are similar to the real and imaginary parts of CEOF1 of this field (not shown), respectively, 


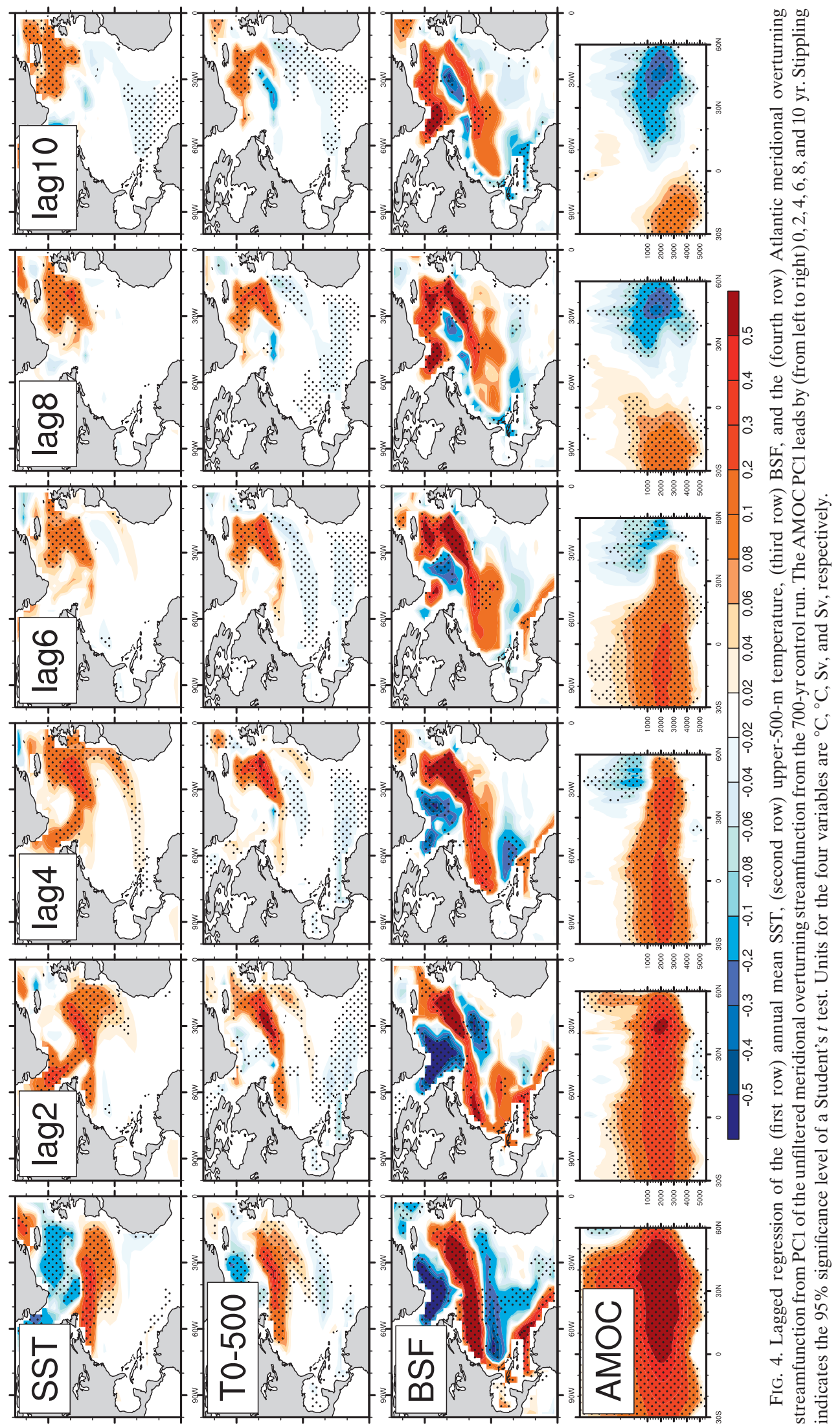



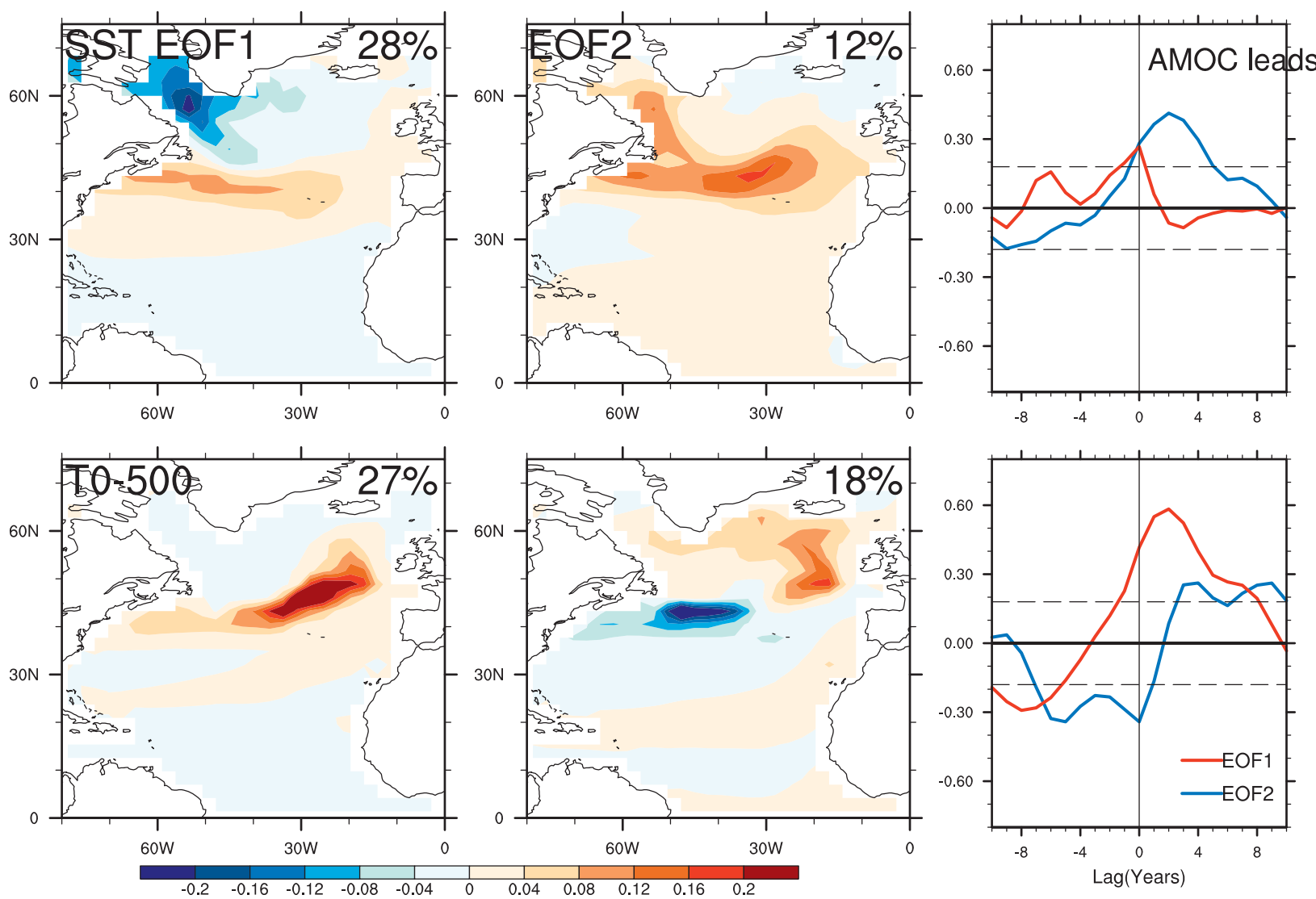

FIG. 5. Leading two EOFs of (top) annual mean SST and (bottom) upper 500-m temperature from the 700-yr control run. The righthand panels show the lag correlations between the leading two PCs and PC1 of the AMOC; the black horizontal dashed line indicates the $95 \%$ significance level.

and suggest that the two patterns vary coherently. The two EOFs together explain $45 \%$ of the total variance and are well separated from EOF3 (10\%). Spectral analysis reveals that the leading PCs have similar temporal characteristics as the PCs of the AMOC, all having enhanced variance in the 10-30-yr frequency band. Within this frequency band, the PCs from the two fields do indeed have significant coherency (figure not shown). More indications of the linkage between the AMOC and this prominent mode of subsurface temperature variability are found by comparing Fig. 5 with Fig. 4. There is close resemblance between the subsurface temperature EOF1 and the subsurface temperature regression map at lag 2, and between EOF2 and the lag- 8 regression maps. This phase relationship is further supported by the significant lag correlation coefficients between $\mathrm{AMOC} \mathrm{PC1}$ and $\mathrm{PC} 1$ and $\mathrm{PC} 2$ of subsurface temperature seen in the bottom right panel of Fig. 5.

Although Fig. 4 shows consistent anticlockwise propagation of SST and subsurface temperature anomalies, this propagation feature is less prominent in SST. This lack of prominence is reflected in the dissimilarity of SST
EOF1 (Fig. 5, upper left) and the structure of the propagating feature in the top row of Fig. 4. It is only when one considers SST EOF2 (Fig. 5, upper right) or SST CEOF2 (not shown) that signatures of the propagating feature are found. SST CEOF2 resembles CEOF1 in upper-500-m temperature but it only explains $16 \%$ of the SST variance.

\section{b. Atmospheric variability}

Danabasoglu (2008) has shown how in the CCSM3 the NAO modulates the subpolar gyre strength and the deep-water formation that spins the AMOC up and down. Here we are more interested in whether AMOC variability can influence atmospheric variability. Owing to the seasonal dependence of the atmospheric response to midlatitude SST (Peng et al. 1997), we will investigate the winter and summer seasons separately. Like many previous studies (Frankignoul et al. 1998), we use lag correlations to detect oceanic impacts on the atmosphere, as instantaneous correlations often reflect an atmospheric pattern that forces the ocean.

We begin with consideration of lags at annual increments to match the analysis of ocean anomalies 
displayed in Fig. 4. During the winter, simultaneous regression maps with AMOC PC1 indicate a dipole surface air temperature (TAS) pattern and a positive NAO/ Arctic Oscillation (AO) (Thompson and Wallace 2000) pattern in sea level pressure (SLP) over the North Atlantic region (Fig. 6). From lags corresponding to SLP leading AMOC PC1, we find this positive NAO appears 8 yr before the AMOC peak and persists until lag 0, consistent with the NAO/AO forcing the AMOC (Danabasoglu 2008; Kwon and Frankignoul 2011). However, 2 yr after the AMOC maximum, the SLP pattern changes to a negative $\mathrm{NAO} / \mathrm{AO}$, and this pattern persists from lag 2 to lag 10 years (we only show lag 5 and lag 10 in Fig. 6). The regressed TAS anomalies are characterized by the so-called cold ocean-warm land (COWL) pattern (Thompson and Wallace 2000) during positive $\mathrm{AO} / \mathrm{NAO}$ at lag 0 and the opposite during the negative AO/NAO phase from lag 2 to lag 10. This is the TAS pattern that Hurrell (1995) has argued is caused by the NAO. The regressed anomalies have weaker amplitude and smaller spatial scales during the summer (Fig. 6, bottom two rows) compared to the winter. From lag 2 to lag 8 , the summer SLP anomaly pattern is similar to the lag 5 regression map (Fig. 6, bottom middle), with positive anomalies over the Barents Sea and Kara Sea and negative SLP anomalies over the Baltic Sea and the North Sea. Since without air-sea coupling atmospheric internal variability possesses a white spectrum for periods longer than a year, long-lasting SLP anomalies like those in Fig. 6 indicate the influence of SST on the atmosphere.

Unfortunately, with only the control run, we are unable to determine whether the lag-5 year negative AO/NAO pattern is forced by the North Atlantic SST anomalies alone or by the SST anomalies in both midlatitude ocean basins because we find that SST anomalous patterns tend to occur simultaneously in the North Pacific and North Atlantic, even in monthly data. Since many factors, including nonlinearity, can add complexity to the atmospheric response to midlatitude SST anomalies (Kushnir et al. 2002), we are reluctant to draw further conclusions from the control run beyond what Fig. 6 provides.

\section{Predictability of the AMOC}

To quantify the predictability that actually exists for the CCSM3 AMOC, we use the A1B and Commitment ensembles. First we examine the initial value predictability in the prominent features of the 10-30-yr variability presented in section 3 . Since we found the natural variability in this range is largely represented by a dynamically linked pair of patterns and since the patterns together may be more predictable than each individually (TB2011), we first focus on the combined predictability in the linked pair.

We project the unfiltered annual mean initial-value component of the AMOC in each realization of the large ensembles onto the two patterns associated with the real and imaginary parts of CEOF1 in the control run (Fig. 3, bottom left two panels) to get the corresponding time series. The distributions of these projections at each forecast range are compared against the distribution of states in control run time series, which are calculated by projecting the detrended annual mean control run data onto the same two patterns. We use the univariate relative entropy of the projections onto real CEOF1 and imaginary CEOF1 as well as the bivariate relative entropy of the combined projections to quantify the initial value predictability in these patterns (Fig. 7).

As we have pointed out, relative entropy measures the difference between the predicted and climatological distribution in terms of both mean and spread. To distinguish contributions from the two attributes, we plot these two components as well as the total relative entropy in Fig. 7. For both CEOF1 real and imaginary parts, it only takes about five or six years for the individual spread to grow as large as the climatological spread. The dispersion of the two combined patterns is predictable for several more years, and the additional predictability is caused by the off-diagonal elements of the covariance matrix. The signal contributes more to the predictability than does the spread. This is true for the CEOF1 real part even in the first year of the integration when the ensemble spread is small. As for the CEOF1 imaginary part, the signal and spread make almost equal contributions to the total relative entropy in the first year, an indication that the initial condition in these experiments has a small projection onto this pattern. But, for this pattern the signal actually grows from year 2 to year 4, while information in the spread keeps decaying —-so quickly that the signal becomes the dominant contributor to the total relative entropy for this pattern too.

Comparing the left two columns of the bottom row of Fig. 7, we note that after the first 2 years, the imaginary part is more predictable than the real part. As we will see in the next section, this is primarily a result of the initial large projection onto the monopole pattern of the real part of CEOF1 evolving to the dipole of the imaginary part of CEOF1, much like the behavior of the dominant mode in the control. Interestingly, we would come to the opposite conclusion regarding the relative predictability of these two patterns if we had only taken spread into account. As the two leftmost panels of the top row of Fig. 7 show, the dispersion relative entropy of the imaginary part of CEOF1 is less than for the real part at all ranges and saturates one or two years earlier. 

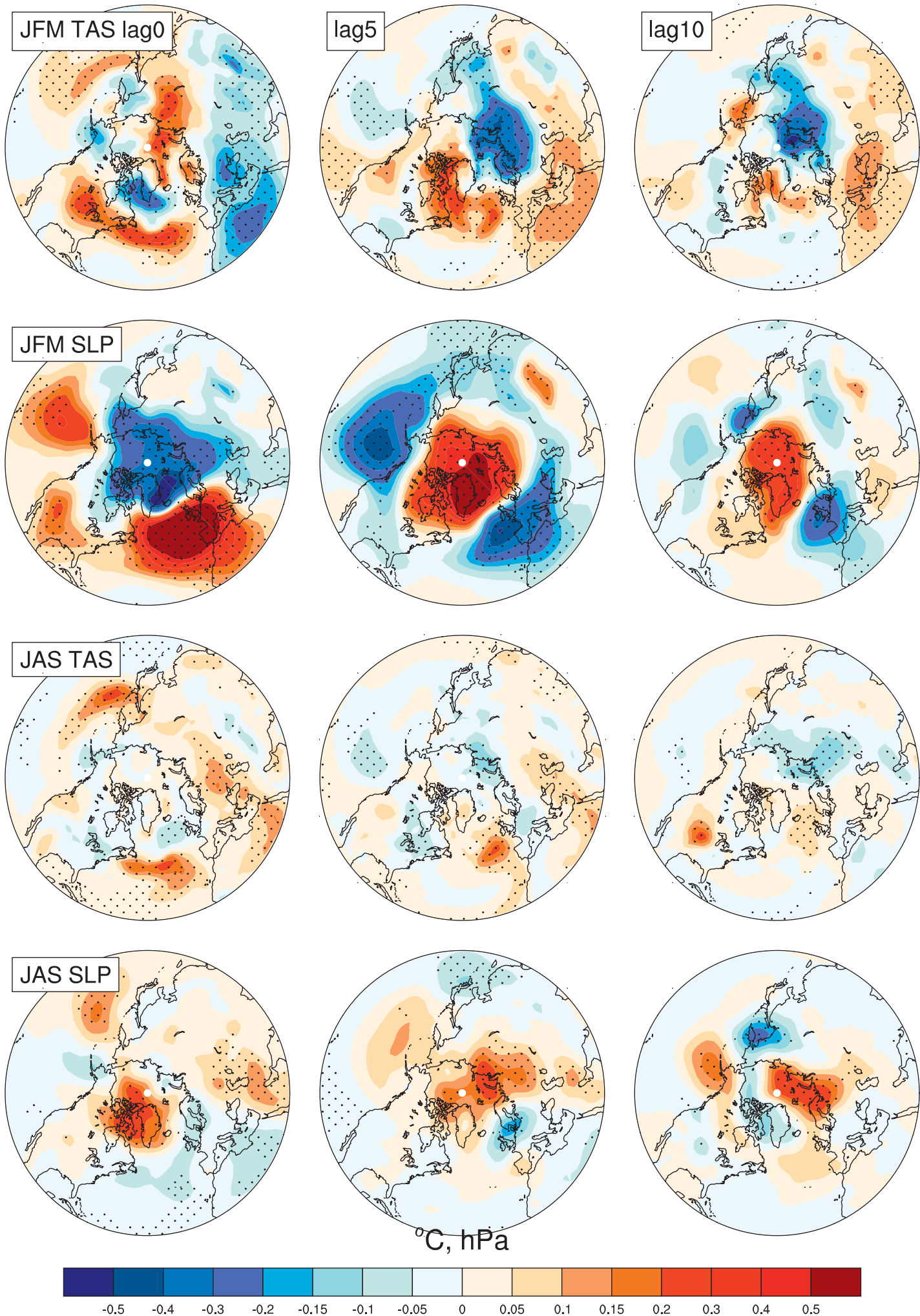

FIG. 6. Lagged regression of the (top to bottom) JFM TAS, JFM SLP, JAS TAS, and JAS SLP from PC1 of the AMOC from the 700-yr control run. The AMOC PC1 leads the atmospheric fields by (left to right) 0, $5 \mathrm{yr}$, and $10 \mathrm{yr}$. Stippling indicates the 95\% significance level from a Student's $t$ test. Temporal 1-2-1 smoothing has been applied to TAS and SLP seasonal means to remove the ENSO signals, which show strong biennial variability in the CCSM3. 

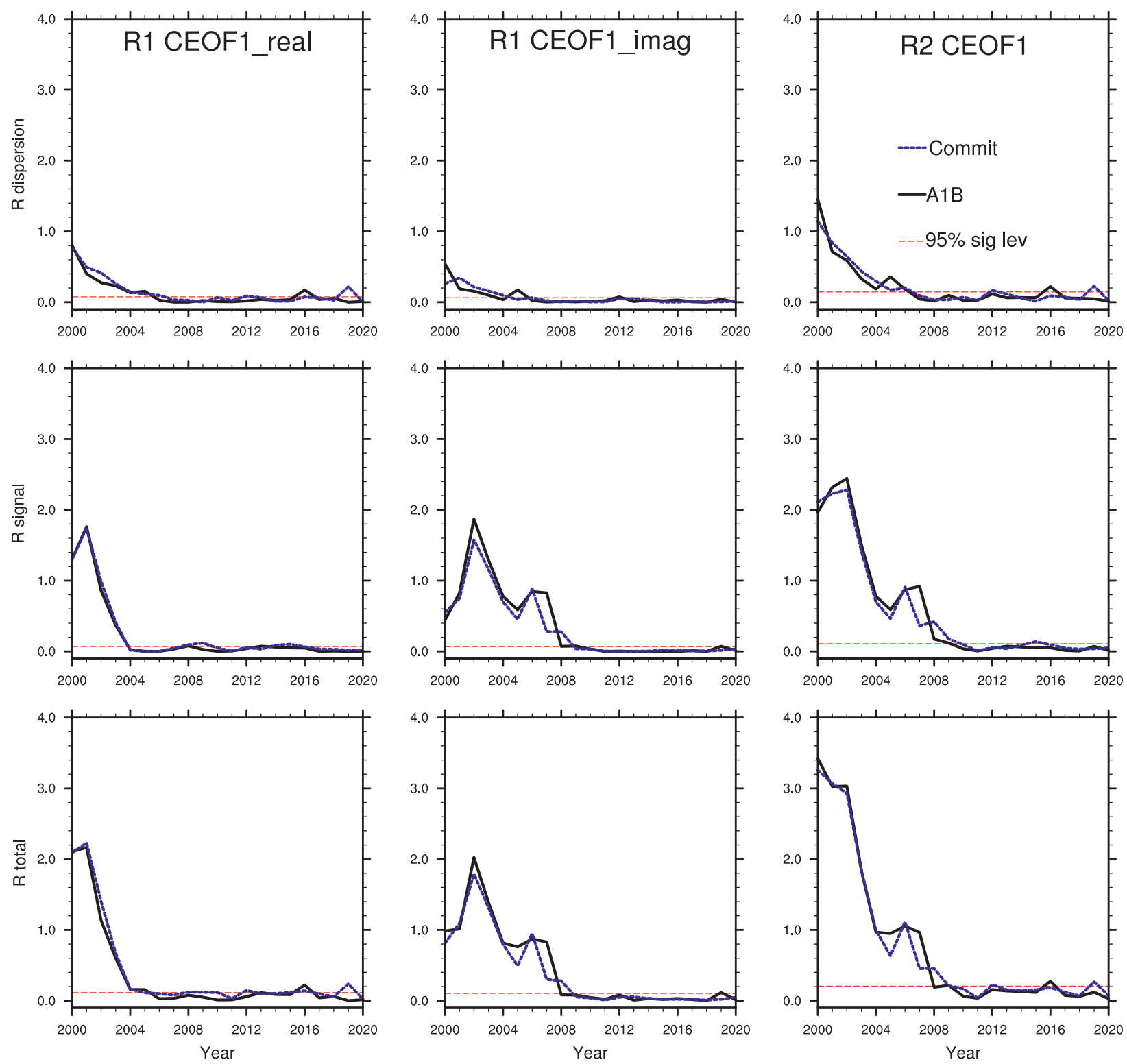

FIG. 7. Relative entropy for the initial value component of the Atlantic overturning streamfunction represented by its R1 CEOF1 (left) real and (middle) imaginary parts in the $\mathrm{A} 1 \mathrm{~B}$ and Commitment ensembles and (right) the R2 CEOF1. The top to bottom panels represent dispersion and signal components of relative entropy and the total relative entropy. Red dashed lines indicate the 95th percentile of relative entropy values from ensembles of 40 random states in the control run. R1 and R2 stands for univariate and bivariate relative entropy, respectively.

Taking into account both patterns, we find the prominent mode of the $10-30$-yr variability in the AMOC is predictable for about 9-10 years (Fig. 7, bottom right), which is double the predictability in the leading pattern alone (Fig. 7, bottom left). In all panels in Fig. 7, the A1B and Commitment ensembles have close resemblance, which is another indication of the significance of the initial value predictability that we are quantifying. To check on how sensitive our results are to the particular initial ocean/land/sea ice state used in the A1B and
Commitment experiments, we have repeated the analysis with the three other ensembles. There is good agreement among all five experiments for the dispersion component of relative entropy, but we find relatively large variations in the signal component. Among the five experiments, the propagation of signals from the CEOF1 real to imaginary parts is most apparent in the A1B and Commitment ensembles, whose initial conditions have stronger projections onto the CEOF1 real part than for the other three ensembles. 


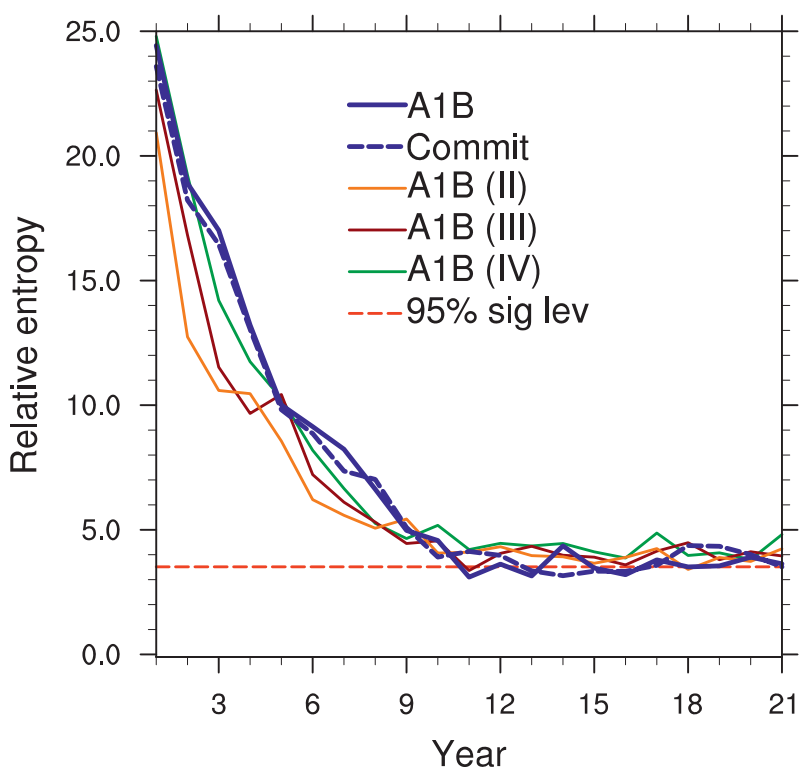

FIG. 8. Relative entropy of the initial value component of the Atlantic meridional overturning streamfunction represented by its leading 15 EOFs in the A1B, Commitment, A1B(II), A1B(III), and $\mathrm{A} 1 \mathrm{~B}(\mathrm{IV})$ ensembles. The red dashed line is the 95 th percentile of relative entropy from ensembles of 40 random states.

It turns out that adding more patterns to represent the AMOC does extend its initial-value predictability limit but not dramatically. Figure 8 shows the relative entropy calculated from the 15 leading EOFs. Together they explain $94 \%$ of the interannual variance. With this representation the AMOC is predictable for 11-13 years in the $\mathrm{A} 1 \mathrm{~B}$ and Commitment ensembles, only a few years longer than what we find for CEOF1. Nevertheless, it suggests that some less prominent patterns are possibly more predictable than the leading EOFs. The most prominent modes, which may have more evident climate impacts due to either larger spatial structures or stronger temporal variability, are not necessarily the most predictable patterns. Considering the three other A1B ensembles, we find that, although there are some variations among the ensembles in terms of relative entropy values in the first decade and the exact year when the curves dip under the threshold, overall information from the initial state is lost after about a decade.

Bryan et al. (2006) roughly estimated that in the CCSM3 the North Atlantic maximum overturning streamfunction started to decline from the control-run mean values after about 40 years of increasing $\mathrm{CO}_{2}$ (at the rate of $1 \%$ per year), resulting in a weakening of 2 to $2.5 \mathrm{~Sv}$ at the time of $\mathrm{CO}_{2}$ doubling. Here, in large ensembles branched from a twentieth-century experiment instead of a control run, we find that we can detect the trend, as indicated by the forced predictability, much earlier. For comparison, initial value and forced predictability in the AMOC's dominant linked pair of patterns and in the leading $15 \mathrm{EOFs}$ are shown in Fig. 9 (left column). The black curves represent the total predictability, which is quantified by comparing the raw predicted states with the climatological distribution in year 1999. It has the same characteristic U shape that BT2010 found for subsurface temperature. Note that the time scale associated with the $\mathrm{U}$ shape is different from Cox and Stephenson (2007) and Hawkins and Sutton (2009), who deal with uncertainties from several factors in climate projections. When compared to curves showing relative entropy for the initial value component (blue) and forced component (green), we find the total predictability can be well explained by the initial-value predictability in the first decade and the forced predictability in the second decade. These results show, in a fashion similar to subsurface temperature (BT2010), that the initial value component of the AMOC saturates after about a decade and becomes less important than the forced component one or two years earlier than that.

To enable a more detailed comparison of AMOC predictability to the predictability of near-surface conditions, we have repeated the relative entropy calculations for the mean upper 500-m temperature (Fig. 9, middle column) and SST (right column) in the North Atlantic $\left(20^{\circ}-75^{\circ} \mathrm{N}\right.$, $80^{\circ} \mathrm{W}-0^{\circ}$ ). Interestingly, the upper-500-m temperature seems to be several years more predictable than the AMOC, for both its leading CEOF and for a 15 EOF representation. As shown in section 3, in the CCSM3 the North Atlantic subsurface temperature variability is dominated by variability in the subpolar region, while the AMOC may be influenced by both subpolar and subtropical gyres (Manabe and Stouffer 1999; Zhang 2008). In section 3 we noted strong coherency between the AMOC and subsurface temperature variability for $10-30-y r$ fluctuations and we might expect features closer to the surface to be more susceptible to weather noise, so it is surprising that the AMOC is less predictable. This is also true for the other three A1B ensembles. Another noteworthy feature is that the dominant pair of patterns in the subsurface temperature has a very small forced trend (Fig. 9, top middle), although some subsurface patterns associated with other EOFs have marked trends (Fig. 9, bottom middle).

SST usually has much shorter memory than subsurface fields owing to weather noise. However, SST CEOF2, which is associated with the subsurface propagating feature, is predictable for about a decade (Fig. 9, top right), only 3-4 yr less than CEOF1 of the subsurface temperature. In contrast, SST CEOF1 is predictable for only about five years (figure not shown).

When we decompose the relative entropy based on 15 EOFs in Fig. 9 (bottom) into its dispersion and signal components (Fig. 10), we find SST predictability mainly resides in the signal component. The dispersion component 

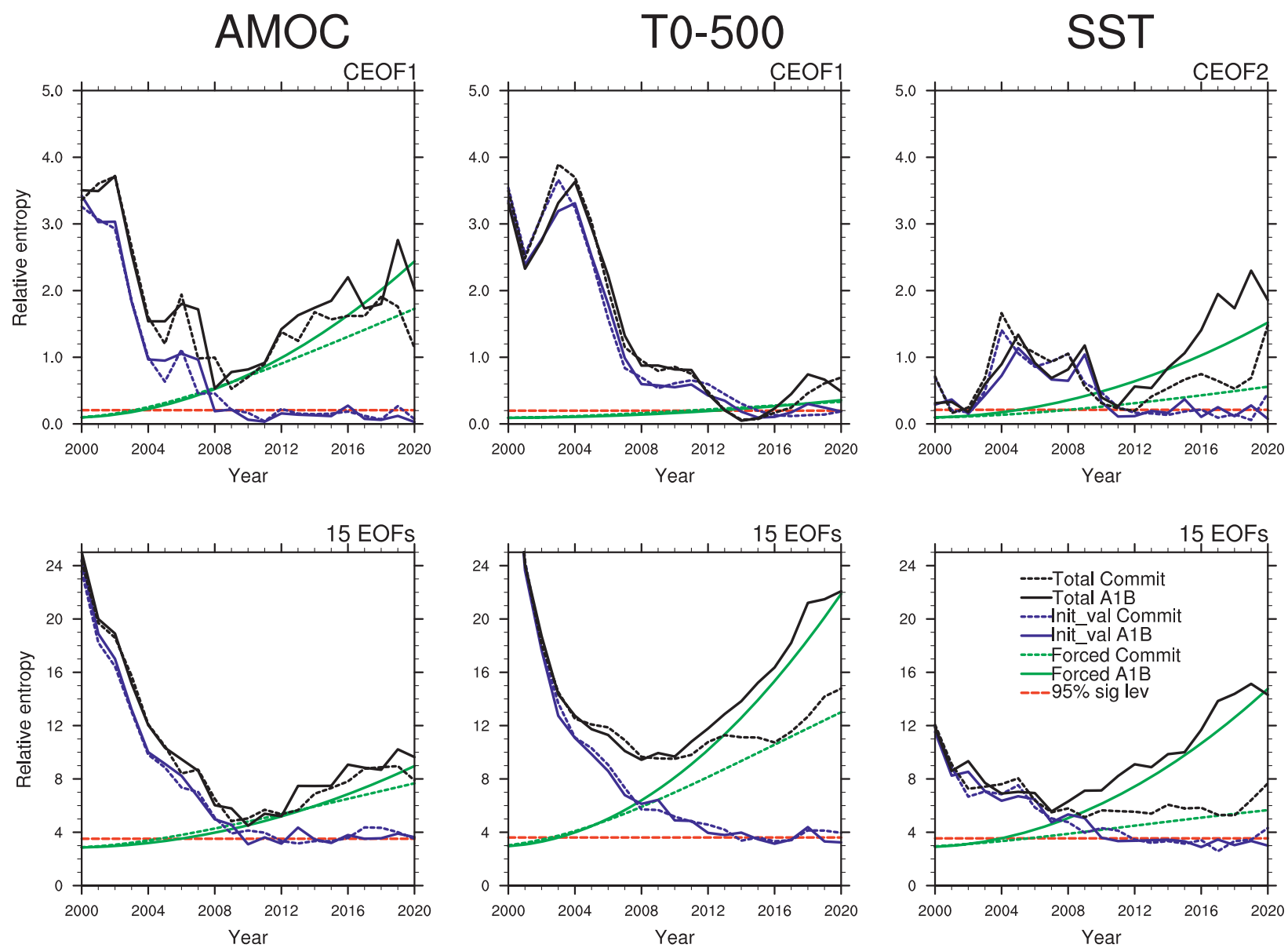

FIG. 9. Relative entropy of the (left) Atlantic meridional overturning streamfunction, (middle) upper 500-m temperature, and (right) SST relative to the 1999 climatology (black) for the initial value component (blue) and the forced component (green). Solid and dashed lines denote the A1B and Commitment ensembles, respectively; the red dashed line indicates the 95th percentile of relative entropy from ensembles of 40 random states in the control run. In the top panels the overturning streamfunction and the upper 500-m temperature are represented by CEOF1, and the SST is represented by CEOF2; in the bottom panels all three fields are represented by 15 leading EOFs. The range of the $y$ axes is proportional to the number of degree of freedom of the measured system.

of SST predictability reaches the saturation level in year 5 , while the signals are predictable for about a decade (Fig. 10, right). This is different from predictability characteristics of the meridional overturning circulation and the subsurface temperature, in which both components make comparable contributions (Fig. 10, left and middle columns). In Fig. 7 we have shown that for Atlantic meridional overturning streamfunction CEOF1, the signal component makes more contribution to the predictability than the dispersion component; the contrast becomes smaller here with more patterns included (Fig. 10, left).

\section{Predictability of the surface climate}

If the atmosphere reacts to the ocean or other boundary conditions that have long memories, then it may have long initial-value predictability. In section 3 we showed that in the control run there are negative NAO-like surface circulation and air temperature anomalies 5-10 yr following the peak of the AMOC PC1 that must be forced by SST anomalies associated with the $10-30$-yr variability in the ocean. In this section we will investigate to what degree this behavior translates into surface predictability by analyzing the A1B and Commitment ensembles. We will only focus on the first decade since thereafter there is not much initial-value predictability left in the ocean and predictability mainly comes from the forced response.

To learn about the structure of the signals in the ocean that potentially impact the atmosphere, we plot the ensemble means of the initial value component of the AMOC, upper 500-m temperature and SST for every second year during the first decade of the experiments (Fig. 11). One-two-one temporal smoothing has been applied so as to minimize the biennial ENSO signals 


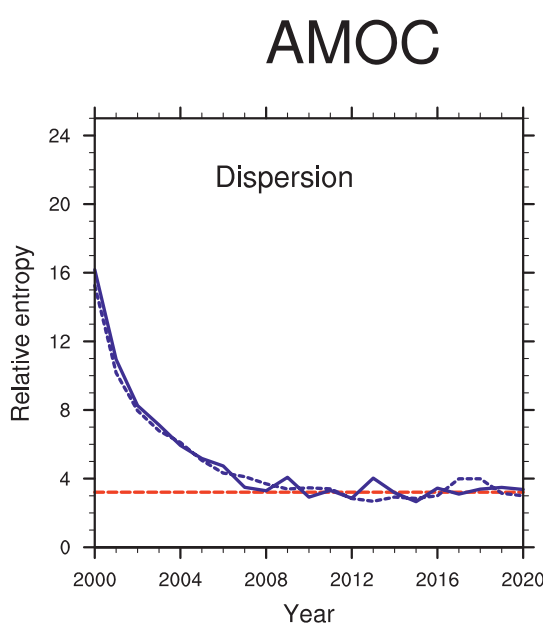

T0-500
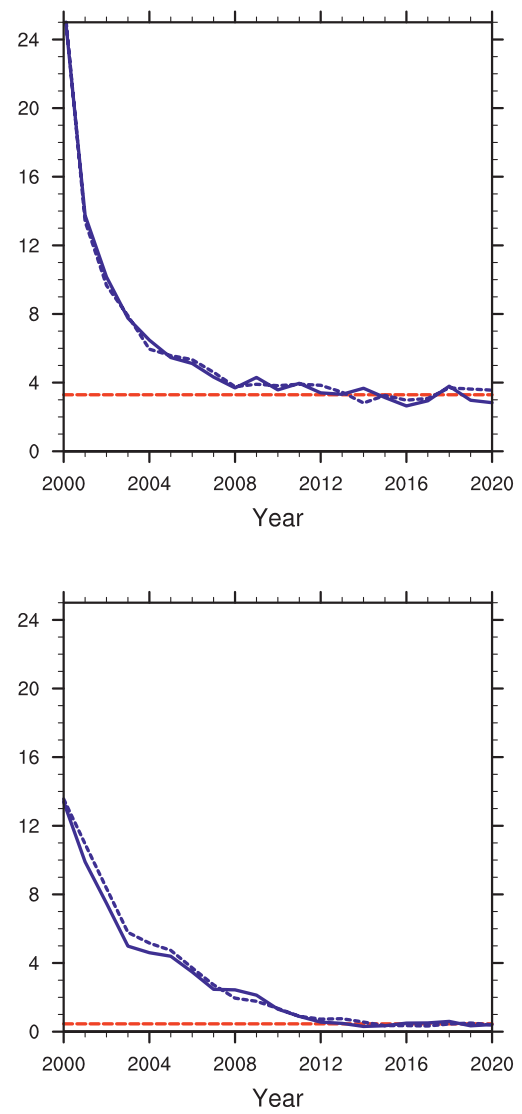

SST
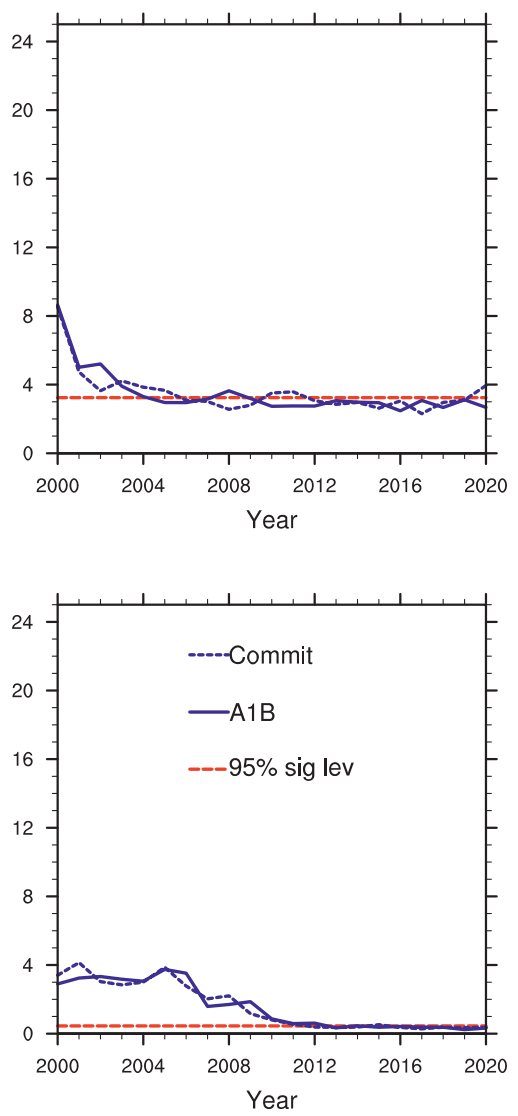

FIG. 10. The (top) dispersion and (bottom) signal components of relative entropy of the initial value component of the (left) Atlantic meridional overturning streamfunction, (middle) upper 500-m temperature, and (right) SST; the short dashed line indicates the 95\% significance level derived from the control run. Each field is represented by its leading 15 EOFs.

(W. D. Collins et al. 2006). Here we average results from the two ensembles because each individual ensemble shows similar features, which is an indication of statistical significance. The initial AMOC state (bottom left panel of Fig. 11) is similar in structure to the leading EOF in the control run, though its sign is opposite to that plotted in Fig. 2. Moreover, the evolution of this feature in the experiments (bottom row of Fig. 11) is very similar to the typical intrinsic evolution of EOF1 documented in Fig. 4, with the anomalies taking on a dipolar structure 4-6 yr after the peak of the monopole. Also similar to the control run (Fig. 4), there are cold subsurface temperature anomalies (Fig. 11, middle row) propagating anticlockwise in the subpolar gyre during the weakening of the monopole. Although the propagation of the SST anomalies (Fig. 11, top row) is less robust in the large ensemble runs, they also agree with the control run in years 5-10 in that the subpolar gyre becomes dominated by cold SSTs just as it became covered by warm SSTs for the opposite polarity situation in Fig. 4.
The next question is whether there are positive NAOlike surface circulation and air temperature anomalies in the large ensembles resulting from the cold subpolar SSTs, as expected from the control run behavior. The ensemble-mean initial value components of TAS and SLP averaged from year 5 to year 10 are presented in Fig. 12 (left column) and, again, we investigate the winter and summer seasons separately. To facilitate the comparison with typical AMOC behavior, we regress these fields against negative AMOC PC1 in the control run (since year 1 exhibits a strong negative EOF1 pattern). These results are plotted in the right column of Fig. 12 in terms of average values for regressions of lag 4-9 years. The regression maps are similar to the lag-5 regression maps in Fig. 6 except that the sign of the anomalies is reversed. Comparing the left and right columns of the figure we see that during January-March (JFM) of years $5-10$, the ensemble mean TAS and SLP field evolution has some similarity to the evolution seen in the control in that both have a positive NAO pattern together 

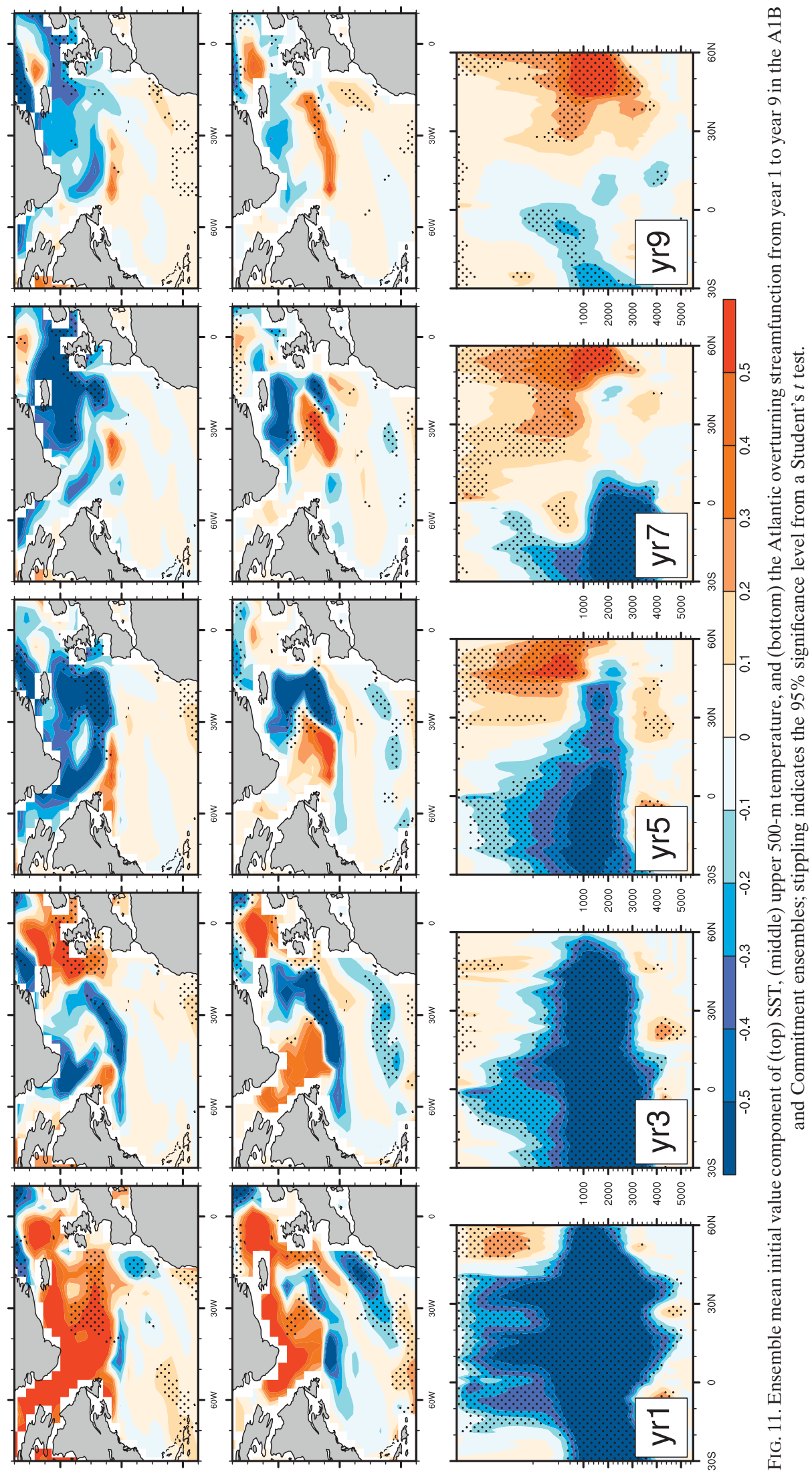

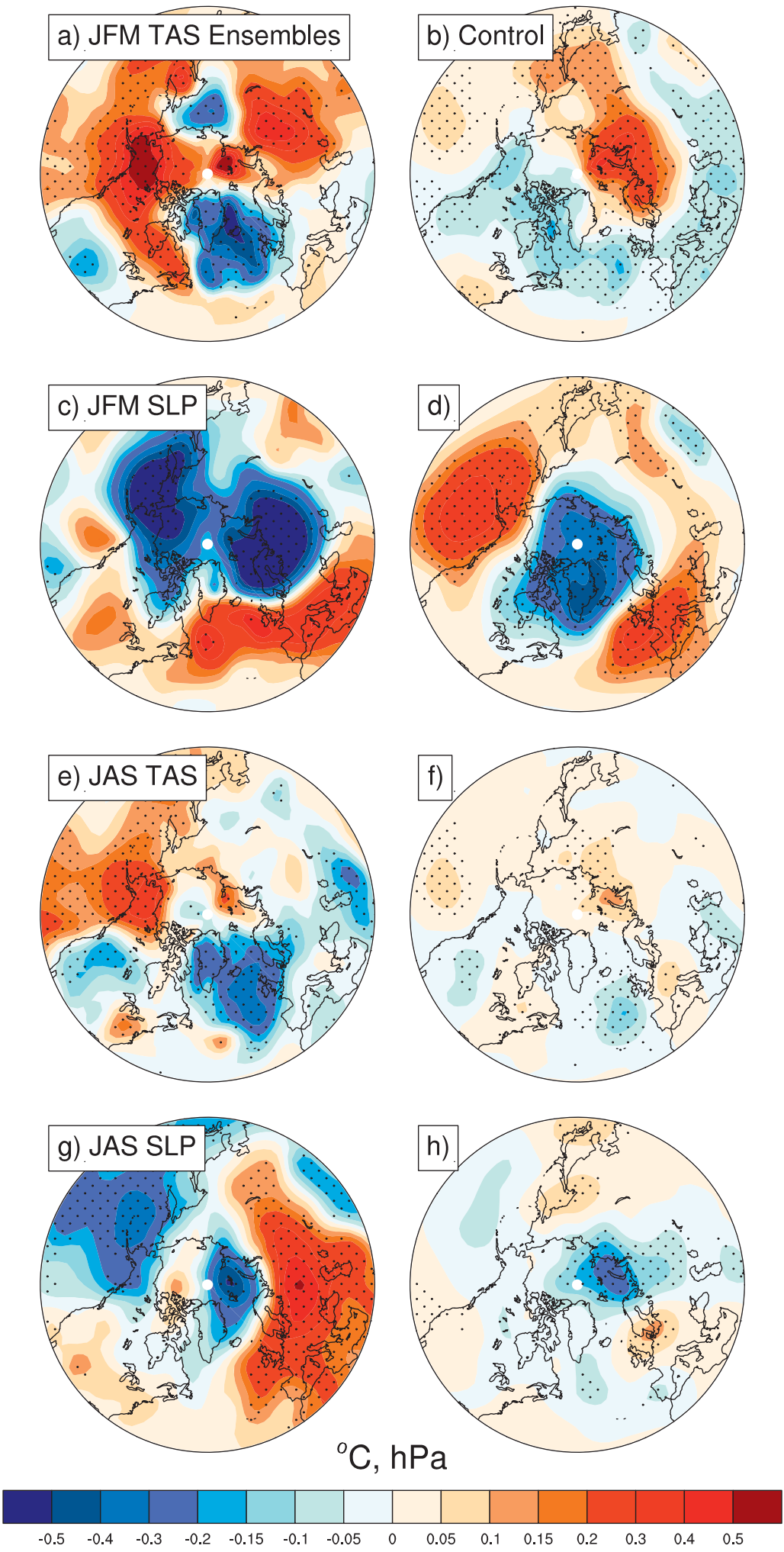

FIG. 12. The (left panels) ensemble mean initial value component of (a) JFM TAS, (b) JFM SLP, (c) JAS TAS, and (d) JAS SLP averaged from year 5 to year 10 in the $\mathrm{A} 1 \mathrm{~B}$ and Commitment ensembles. The right panels are the same fields regressed from AMOC PC1 with 4-9-yr lags in the 700-yr control run. Stippling indicates the $95 \%$ significance level from a Student's $t$ test. 
with cold air temperature over the North Atlantic and warm temperature anomalies over the Eurasia continent.

There are, however, some disagreements between the experiments and the control over the North Pacific. In the control run, the JFM SLP anomalies associated with the Aleutian low and the Icelandic low have the same (positive) sign and similar amplitude (Fig. 12d), and together with low pressure anomalies over the Arctic Ocean they produce a positive AO pattern. In contrast, in the large ensembles the northern Pacific is dominated by low pressure anomalies. It is likely that this mismatch is caused by the fact that SSTs in the North Pacific of the ensemble experiments are quite different from the North Pacific SSTs typically associated with the evolution of the AMOC after a negative PC1 event. As is partially visible in Fig. 12, and more clearly in global plots of the same fields, the evolution of the AMOC in the control tends to be accompanied by North Pacific SSTs that are similar to the CCSM3 Pacific decadal oscillation (PDO). TB2011 have shown in this model that the North Pacific subsurface temperature has decadal predictability but the PDO has weak amplitude in the initial conditions and evolution of these particular experiments. This lack of PDO structure in the ensemble can also be seen in the TAS panels in the left column of Fig. 12.

Comparison of plots for summer and winter in Fig. 12 indicate that during years 5 to 10 the ensemble mean oceanic TAS (and therefore SST) anomalies do not show much seasonal variation in the two basins. There are, however, noticeable seasonal changes in SLP patterns and in TAS over land. The low pressure cell associated with the NAO-like pattern becomes much weaker in summer, with negative anomalies mostly confined to the Greenland, Barents, and Kara Seas. Although the summertime circulation anomalies over the North Atlantic and Europe still show some positive NAO characteristics, the dipole structure is dominated by high pressure anomalies covering most of Europe. Another seasonal change is found in TAS over the continents. During the wintertime, both North America and the Eurasian continent have warm temperature anomalies, which are associated with the positive AO surface circulation anomalies (Thompson and Wallace 2000). These patterns are not found in the summer. The contrast between summer and winter is also apparent in the control, with summer anomalies being much weaker than those in winter (Fig. 12, right column).

Earlier we mentioned that the initial value components of the A1B and Commitment ensembles produce similar AMOC, subsurface temperature, and SST mean signals during the first decade (Fig. 11). It is more difficult to find coherent signals in the atmospheric circulation. For example, when comparing seasonal mean
SLP anomalies in each year from year 5 to 10 , we find substantial differences in the wintertime NAO-like patterns between the two experiments. It is for this reason that we combined the two ensembles and calculated multiyear averages to increase the signal-to-noise ratio when comparing ensemble and control structures in Fig. 12. But, as the rather small number of statistically significant points in Fig. 12c demonstrates, even when 80 realizations and 6-yr averages are used, predictable signals in some key surface fields are difficult to establish. The summertime SLP dipole structure can be better identified in individual years in both ensembles. This suggests that the summertime surface circulation may be more predictable than the winter counterpart due to smaller internal variability. Several previous studies also found a stronger atmospheric response to North Atlantic SST anomalies during the summer season (Sutton and Hodson 2007; Msadek and Frankignoul 2009).

These results indicate that there is a predictable signal in some aspects of surface fields, but the predictability seems to be less pronounced than in the ocean variables. To quantify predictability of the atmospheric fields, we use the same approach used in Fig. 10 for oceanic fields and calculate the relative entropy in the leading 15 EOFs of TAS over land (since the TAS over ocean is similar to SST) and SLP of the Northern Hemisphere $\left(20^{\circ}-90^{\circ} \mathrm{N}\right)$ in both seasons (Fig. 13). The leading 15 EOFs in land TAS represent $86 \%$ and $76 \%$ of the interannual variance in JFM and JAS seasonal means after 1-2-1 smoothing is applied. Compared with the relative entropy in the leading 15 EOFs in the annual mean North Atlantic SST (Fig. 10, bottom right), we find the planetary land TAS anomalies have much lower initial-value predictability in both seasons, probably because they do not have the ocean's inertia to lessen the effects of weather noise. The summertime land TAS is slightly more predictable; nevertheless it loses initial-value predictability after 4 years. For both seasons, the forced predictability in TAS becomes significant and larger than the initial-value predictability after 5 years. Compared with TAS, SLP has even weaker initial-value predictability. The relative entropy of the leading 15 EOFs in JFM and JAS SLP is shown in Fig. 13 (bottom panels). The 15 EOFs together explain $92 \%$ and $84 \%$, respectively, of the interannual variance. SLP from both seasons loses initial-value predictability after two or three years. Unlike TAS, there is no significant forced predictability in SLP.

Similar to section 4, we further decompose the relative entropy in Fig. 13 into the dispersion and signal components. Unlike the ocean fields that show a monotonic decay toward the $95 \%$ significance level in the first decade (Fig. 10, top), the dispersion component of the atmospheric fields is flat through the entire forecast period, and 

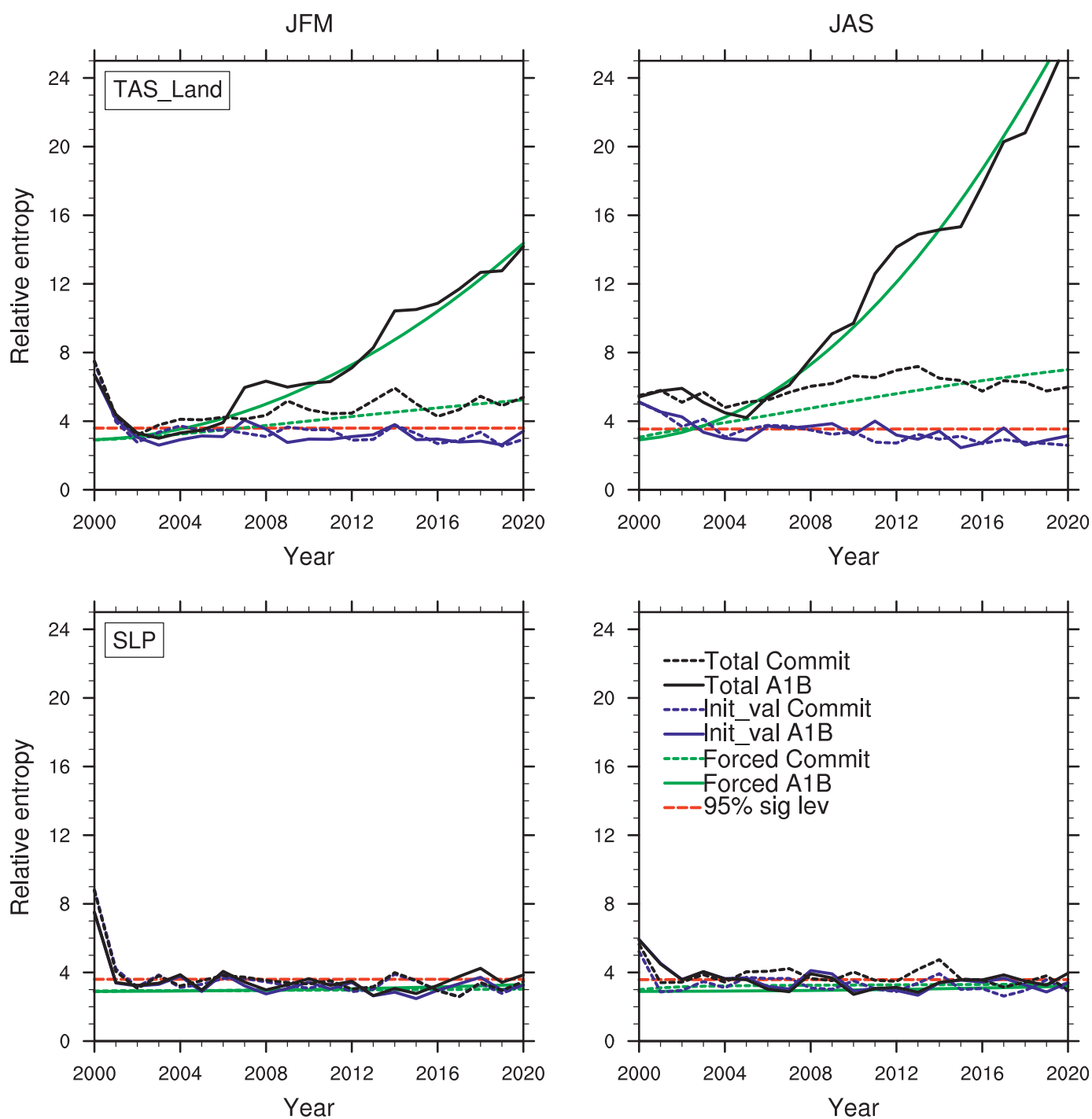

FIG. 13. As in the bottom panels of Fig. 8 but for (left) JFM and (right) JAS seasonal mean (top) TAS over land and (bottom) SLP in the Northern Hemisphere $\left(20^{\circ}-90^{\circ} \mathrm{N}\right)$. Each field is represented by the leading 15 EOFs.

even in the first year the value is very close to the $95 \%$ significance level (figure not shown). This indicates that, although spread in the North Atlantic SST contributes to the predictability in the first five years (Fig. 10, top right), the atmospheric predictability only resides in the mean signals.

In an attempt to better capture the weak predictability in land TAS and SLP, we increase our sample size by combining the two ensembles and recalculate the relative entropy of the initial value component of all the fields. Since the dispersion component of the atmospheric fields is negligible, only the signal component of the relative entropy is presented (Fig. 14, left). Comparing it with Figs. 10 and 12, the change to the estimated predictability of both oceanic and the atmospheric variables is small with doubled sample size. Next we repeat the 80-member analysis with a 5-yr running average applied to the data (Fig. 14, right). The temporal smoothing slightly increases the relative entropy values for all variables. Most importantly, now the relative entropy of the atmospheric fields is above the $95 \%$ significance level in the first decade. Thus, the temporal averaging used in construction of Fig. 12 was crucial in producing significant mean anomalies. Notice, however, that though statistically significant the information in predicted atmospheric fields is very much less than in the ocean fields.

\section{Concluding remarks}

Using a long control run and two "perfect model" large ensemble experiments, we find in CCSM3 that the 

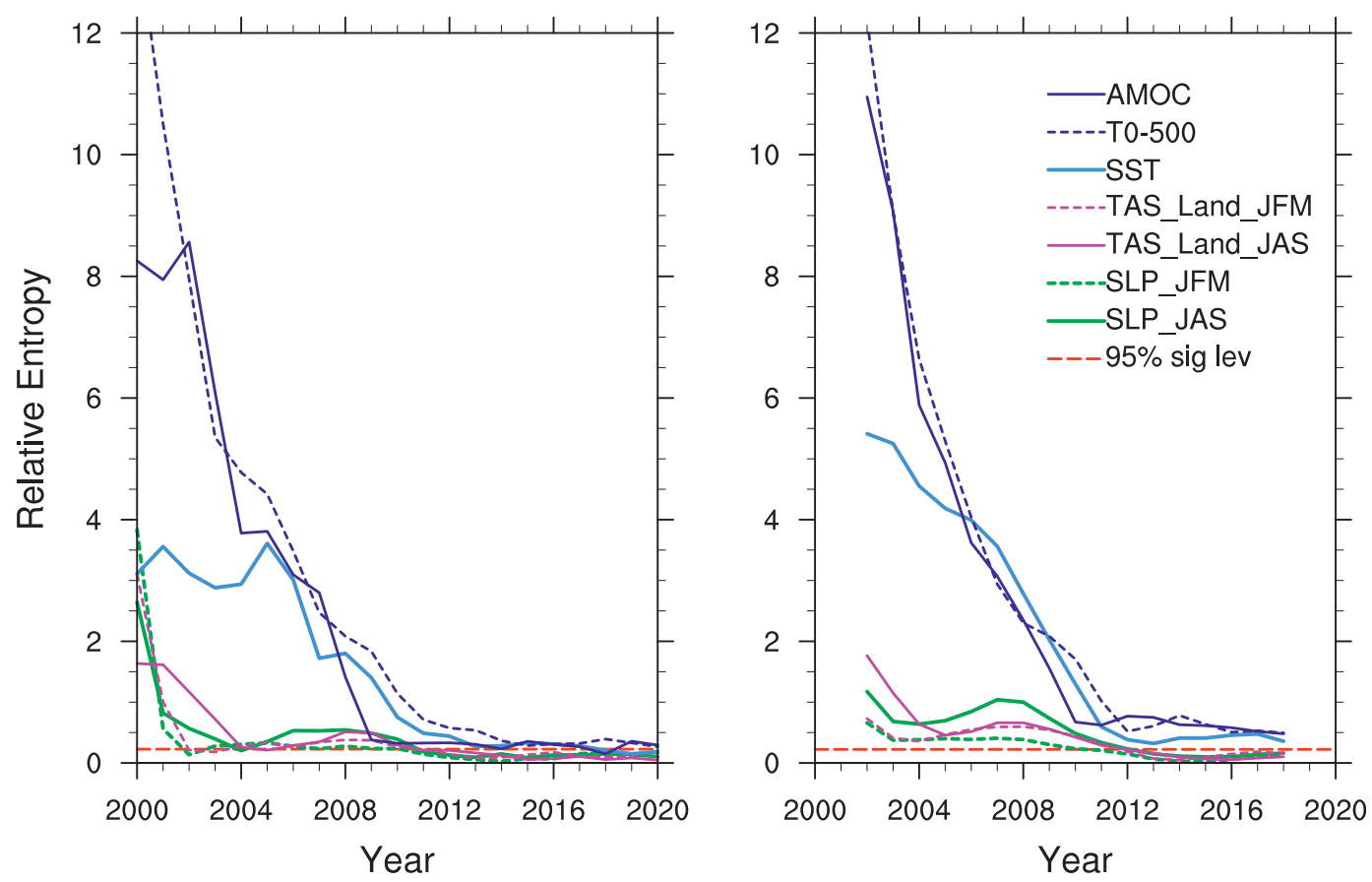

FIG. 14. Signal component of (left) relative entropy of the 80-member initial value component of the Atlantic meridional overturning streamfunction, the North Atlantic upper 500-m temperature and SST, and the Northern Hemisphere $\left(20^{\circ}-90^{\circ} \mathrm{N}\right) \mathrm{JFM}$ and JAS seasonal mean TAS over land and SLP using 15 EOFs; the red horizontal dashed line indicates the $95 \%$ significance level from the control run. but the right-hand panel represents the signal after 5-yr running averaging has been applied to both the large ensemble and control run data.

AMOC is predictable as a result of initial condition information for about a decade; beyond a decade the forced predictability dominates. AMOC initial-value predictability is associated with the $10-30-y r$ variability of an anticlockwise propagating feature in both subsurface temperature and SST in the North Atlantic subpolar region. This feature is represented by the leading two EOFs in the upper 500-m temperature. Alternatively, it corresponds to the pair of patterns that comprise CEOF1, as well as to CEOF2 of SST in the North Atlantic. As a result of this propagating mode, the subpolar region is dominated by warm/cool SST anomalies 5-10 yr after an AMOC maximum/minimum. The resulting SST anomalies can influence the atmospheric surface circulation in both winter and summer seasons, but the atmospheric response is very weak.

The AMOC's initial-value predictability limit that we find in the CCSM3 roughly agrees with results from other climate models in that the AMOC has initial-value predictability on the decadal time scale. However, our method to quantify predictability is quite different from other studies. In most previous studies, predictability is measured only by the spread in the forecast distributions of a univariate AMOC index (Msadek et al. 2010; Pohlmann et al. 2004; M. Collins et al. 2006). If measured that way, as we showed in Fig. 7 (top left), the AMOC EOF1 is only predictable for about six years in the CCSM3. Additional predictability resides in ensemble mean signals and in the tendency of the AMOC EOF1 single-cell pattern to evolve to the EOF2 dipole pattern. Only after we take both factors into account do we find the AMOC can be predictable for about a decade. Since most previous studies may have underestimated the AMOC predictability by neglecting two important contributors that we have included, as well as because most studies employ small ensemble sizes, we think the AMOC in the CCSM3 may be less predictable than in many other fully coupled models.

Another feature that makes our results interesting is that the model that we analyzed has a strong connection between decadal variability of the AMOC and the NAO. In particular, it is known that in this model the NAO tends to drive AMOC variability (Danabasoglu 2008). This connection should decrease AMOC predictability because the NAO is dominated by atmospheric internal variability. However, we find that evolution of the AMOC after peaks in its anomalous amplitude is predictable because of the regular evolution in its structure that occurs after these peaks. Furthermore, the anticlockwise propagating feature in both subsurface 
temperature and SST that follows peaks in AMOC amplitude is even more predictable than the AMOC itself. These SST anomalies can influence the atmosphere, potentially resulting in long predictability in the atmosphere. The relationship between the AMOC and NAO on decadal to multidecadal time scales is poorly understood in nature, but our study provides an example that there still can be decadal initial-value predictability in the ocean and surface climate even if the AMOC is strongly influenced by the NAO.

Although our results suggest there is hope for skillful decadal predictions of atmospheric fields, our study also raises several concerns. First, even after combining the two 40-member ensembles and calculating 6-yr averages, we find the atmospheric signals generated by the predictable CCSM3 ocean signals are weak relative to unpredictable atmospheric fluctuations. As only 3 to 10 ensemble members are required for the CMIP5 decadal prediction experiments (Taylor et al. 2011), it will be difficult to determine whether the predictions of models with similar properties are statistically significant. Our second concern involves the Pacific. Many studies have shown that the North Pacific also has decadal predictability, and it too can affect the hemispheric atmospheric circulation. In CCSM3 the two northern ocean basins are independent enough that it is necessary to initialize and represent prominent variability in both basins to predict hemispheric atmospheric circulation anomalies. Predicting the North Pacific can be especially important for North America because of its downstream location (Meehl et al. 2010).

In the CCSM3 experiments that we have analyzed, the climate is changing. This complicates our analysis, but it is a source of predictability over and above that coming from predictable natural ocean variability. In the first 20 years of these experiments, trends in the AMOC are quite similar in the two scenarios that we considered, and they become the dominant source of predictability after a decade. In contrast, the surface air temperature and SST respond to the GHG forcing much faster. These findings imply that, even for decadal predictions, external forcing changes must be taken into account. Conversely, our results here for the North Atlantic and in BT2010 for subsurface temperature in other basins indicate that details in GHG evolution are not crucial for predictions during the first decade of projections.

It is also important to keep in mind various limitations to our conclusions due to model bias and the experimental design. The upper limit of AMOC predictability concerns the behavior of a perfect model. The predictability limit that we estimate here does not necessarily translate into predictive skill. In addition to predictability error growth, forecast skill is also degraded by model errors. One striking consequence of these errors is model drift, resulting from model bias (G. Danabasoglu, NCAR, 2011, personal communication). Another limitation is that most of our results are based on only one ocean initial state. Although in Fig. 8 we have measured AMOC predictability using three additional ocean initial states and find it is similar to the predictability limits in our primary experiments, we cannot exclude the possibility that some ocean states may be more predictable than others. The perturbed ensemble experiment approach has a fundamental limitation that only a few initial conditions can be investigated owing to its large computational cost. We have had encouraging results when we tested alternative methods that enable one to systematically consider predictability for each state along a model's long control trajectory (Branstator et al. 2011). A third limitation, as mentioned in the introduction, is that the findings in the study are only valid for T42 CCSM3. Since AMOC variability varies a great deal from one climate model to another (Hurrell et al. 2009), we expect different conclusions for other models. For example, the NAO response to the AMOC maximum is so weak as to be statistically insignificant in a shorter T85 CCSM3 control run (Danabasoglu 2008; Kwon and Frankignoul 2011). For this reason, we strongly advocate that each modeling group that provides decadal predictions for CMIP5 also conduct predictability studies.

Acknowledgments. The authors acknowledge helpful comments from Gokhan Danabasoglu and Rym Msadek, and three anonymous reviewers. This work was supported by the DOE under Cooperative Agreements DE-FC02-97ER62402 and DE-SC0005355.

\section{REFERENCES}

Alexander, M., and Coauthors, 2006: Extratropical atmosphereocean variability in CCSM3. J. Climate, 19, 2496-2525.

Branstator, G., and H. Teng, 2010: Two limits of initial-value decadal predictability in a CGCM. J. Climate, 23, 6292-6311.

,-- G. A. Meehl, M. Kimoto, J. R. Knight, M. Latif, and A. Rosati, 2011: Systematic estimates of initial value decadal predictability for six AOGCMs. J. Climate, in press.

Bryan, F. O., G. Danabasoglu, N. Nakashiki, Y. Yoshida, D.-H. Kim, J. Tsutsui, and S. C. Doney, 2006: Response of the North Atlantic thermohaline circulation and ventilation to increasing carbon dioxide in CCSM3. J. Climate, 19, 2382-2397.

Collins, M., 2002: Climate predictability on interannual to decadal time scales: The initial value problem. Climate Dyn., 19, 671-692.

_ and B. Sinha, 2003: Predictability of decadal variations in the thermohaline circulation and climate. Geophys. Res. Lett., 30, 1306, doi:10.1029/2002GL016504.

_ , and Coauthors, 2006: Interannual to decadal climate predictability in the North Atlantic: A multimodel-ensemble study. J. Climate, 19, 1195-1203. 
Collins, W. D., and Coauthors, 2006: The Community Climate System Model version 3 (CCSM3). J. Climate, 19, 2122-2143.

Cox, P., and D. Stephenson, 2007: A changing climate for prediction. Science, 317, 207-208.

Dai, A., A. Hu, G. A. Meehl, W. M. Washington, and W. G. Strand 2005: Atlantic thermohaline circulation in a coupled general circulation model: Unforced variations versus forced changes. J. Climate, 18, 3270-3293.

Danabasoglu, G., 2008: On multidecadal variability of the Atlantic meridional overturning circulation in the Community Climate System Model version 3. J. Climate, 21, 5524-5544.

Delworth, T. L., and R. J. Greatbatch, 2000: Multidecadal thermohaline circulation variability driven by atmospheric surface flux forcing. J. Climate, 13, 1481-1495.

_, and M. E. Mann, 2000: Observed and simulated multidecadal variability in the Northern Hemisphere. Climate Dyn., 16, 661-676.

_ S. Manabe, and R. J. Stouffer, 1993: Interdecadal variations of the thermohaline circulation in a coupled ocean-atmosphere model. J. Climate, 6, 1993-2011.

— , and Coauthors, 2008: The potential for abrupt change in the Atlantic meridional overturning circulation. Abrupt climate change, USGS Final Rep., Synthesis and Assessment Product $3.4,258-359$.

Dong, B., and R. T. Sutton, 2005: Mechanism of interdecadal thermohaline circulation variability in a coupled ocean-atmosphere GCM. J. Climate, 18, 1117-1135.

Enfield, D. B., A. M. Mestas-Nunez, and P. J. Trimble, 2001: The Atlantic multidecadal oscillation and its relation to rainfall and river flows in the continental U.S. Geophys. Res. Lett., 28 , 2077-2080.

Frankignoul, C., A. Czaja, and B. L’Heveder, 1998: Air-sea feedback in the North Atlantic and surface boundary conditions for ocean models. J. Climate, 11, 2310-2324.

Griffies, S. M., and K. Bryan, 1997: Predictability of North Atlantic multidecadal climate variability. Science, 275, 181-184.

Hawkins, E., and R. Sutton, 2009: The potential to narrow uncertainty in regional climate predictions. Bull. Amer. Meteor. Soc., 90, 1095-1107.

Hurrell, J. W., 1995: Decadal trends in the North Atlantic Oscillation: Regional temperatures and precipitation. Science, 269, 676679.

—- and Coauthors, 2009: Decadal climate variability, predictability, and prediction: Opportunities and challenges. Proc. OceanObs '09, Venice, Italy, European Space Agency, 17 pp. [Available online at https://abstracts.congrex.com/scripts/ jmevent/abstracts/FCXNL-09A02b-1868863-1-OceanObs09_ Hurrell_Revised-v2.pdf.]

Jungclaus, J. H., H. Haak, M. Latif, and U. Mikolajewicz, 2005: Arctic North Atlantic interactions and multidecadal variability of the meridional overturning circulation. J. Climate, $\mathbf{1 8}$, 4013-4031.

Kleeman, R., 2002: Measuring dynamical prediction utility using relative entropy. J. Atmos. Sci., 59, 2057-2072.

Knight, J. R., C. K. Folland, and A. A. Scaife, 2006: Climate impacts of the Atlantic multidecadal oscillation. Geophys. Res. Lett., 33, L17706, doi:10.1029/2006GL026242.

Kushnir, Y., and I. Held, 1996: Equilibrium atmospheric response to North Atlantic SST anomalies. J. Climate, 9, 1208-1220.

, W. A. Robinson, I. Blade, N. M. J. Hall, S. Peng, and R. Sutton, 2002: Atmospheric GCM response to extratropical SST anomalies: Synthesis and evaluation. J. Climate, 15, 2233 2256.
Kwon, Y.-O., and C. Frankignoul, 2011: Stochastically-driven multidecadal variability of the Atlantic meridional overturning circulation in CCSM3. Climate Dyn., doi:10.1007/ s00382-011-1040-2, in press.

Landsea, C. W., R. A. Pielke, A. M. Mestas-Nunez, and J. A. Knaff, 1999: Atlantic basin hurricanes: Indices of climatic changes. Climatic Change, 42, 89-129.

Large, W. G., and G. Danabasoglu, 2006: Attribution and impacts of upper-ocean biases in CCSM3. J. Climate, 19, 2325-2346.

Latif, M., M. Collins, H. Pohlmann, and N. Keenlyside, 2006: A review of predictability studies of Atlantic sector climate on decadal scales. J. Climate, 19, 5971-5987.

Lorenz, E. N., 1963: Deterministic nonperiodic flow. J. Atmos. Sci., 20, 130-141.

Lu, J., and T. L. Delworth, 2005: Oceanic forcing of the late 20th century Sahel drought. Geophys. Res. Lett., 32, L22706, doi:10.1029/2005GL023316.

Majda, A. J., R. V. Abramov, and M. J. Grote, 2005: Information Theory and Stochastics for Multiscale Nonlinear Systems. CRM Monogr., Vol. 25, American Mathematical Society, 133 pp.

Manabe, S., and R. J. Stouffer, 1999: The role of thermohaline circulation in climate. Tellus, 51A, 91-109.

Marshall, J., and Coauthors, 2001: North Atlantic climate variability: Phenomena, impacts and mechanisms. Int. J. Climatol., 21, 1863-1898.

Meehl, G. A., W. M. Washington, W. D. Collins, J. M. Arblaster, A. Hu, L. E. Buja, W. G. Strand, and H. Teng, 2005: How much more global warming and sea level rise? Science, 307, 1769-1772.

— , and Coauthors, 2006: Climate change projections for the twenty-first century and climate change commitment in the CCSM3. J. Climate, 19, 2597-2616.

— Bull. Amer. Meteor. Soc., 90, 1467-1485.

- A. Hu, and C. Tebaldi, 2010: Decadal prediction in the Pacific region. J. Climate, 23, 2959-2973.

Msadek, R., and C. Frankignoul, 2009: Atlantic multidecadal oceanic variability and its influence on the atmosphere in a climate model. Climate Dyn., 33, 45-62.

—, K. W. Dixon, T. L. Delworth, and W. Hurlin, 2010: Assessing the predictability of the Atlantic meridional overturning circulation and associated fingerprints. Geophys. Res. Lett., 37, L19608, doi:10.1029/2010GL044517.

Park, W., and M. Latif, 2005: Ocean dynamics and the nature of air-sea interactions over the North Atlantic at decadal time scales. J. Climate, 18, 982-995.

Peng, S., W. A. Robinson, and M. P. Hoerling, 1997: The modeled atmospheric response to midlatitude SST anomalies and its dependence on background circulation. J. Climate, 10, 971-987.

Pohlmann, H., M. Botzet, M. Latif, A. Roesch, M. Wild, and P. Tschuck, 2004: Estimating the decadal predictability of a coupled AOGCM. J. Climate, 17, 4463-4472.

Saravanan, R., and J. C. McWilliams, 1998: Advective oceanatmosphere interaction: An analytical stochastic model with implications for decadal variability. J. Climate, 11, 165-188.

-, G. Danabasoglu, S. C. Doney, and J. C. McWilliams, 2000: Decadal variability and predictability in the midlatitude oceanatmosphere system. J. Climate, 13, 1073-1097.

Solomon, A., and Coauthors, 2011: Distinguishing the roles of natural and anthropogenically forced decadal climate variability: Implication for prediction. Bull. Amer. Meteor. Soc., 92, 141-156. 
Sutton, R. T., and M. R. Allen, 1997: Decadal predictability of North Atlantic sea surface temperature and climate. Nature, 388, 563-567. , and D. L. R. Hodson, 2005: Atlantic Ocean forcing of North American and European summer climate. Science, 309, 115-118. , and - 2007: Climate response to basin-scale warming and cooling of the North Atlantic Ocean. J. Climate, 20, 891-907.

Taylor, K. E., R. J. Stouffer, and G. A. Meehl, 2011: A summary of the CMIP5 experimental design. PCMDI Rep., 32 pp. [Available online at http://cmip-pcmdi.llnl.gov/cmip5/docs/ Taylor_CMIP5_design.pdf.]

Teng, H., and G. Branstator, 2011: Initial-value predictability of prominent modes of North Pacific subsurface temperature in a CGCM. Climate Dyn., 36, 1813-1834, doi:10.1007/s00382010-0749-7.
Thompson, D. W., and J. M. Wallace, 2000: Annular modes in the extratropical circulation. Part I: Month-to-month variability. J. Climate, 13, 1000-1016.

Timmermann, A., M. Latif, R. Voss, and A. Grötzner, 1998: Northern Hemisphere interdecadal variability: A coupled airsea mode. J. Climate, 11, 1906-1931.

von Storch, H., and F. W. Zwiers, 1999: Statistical Analysis in Climate Research. Cambridge University Press, 484 pp.

Zhang, R., 2008: Coherent surface-subsurface fingerprint of the Atlantic meridional overturning circulation. Geophys. Res. Lett., 35, L20705, doi:10.1029/2008GL035463.

— oscillations on India/Sahel rainfall and Atlantic hurricanes. Geophys. Res. Lett., 33, L17712, doi:10.1029/2006GL026267. 
Copyright of Journal of Climate is the property of American Meteorological Society and its content may not be copied or emailed to multiple sites or posted to a listserv without the copyright holder's express written permission. However, users may print, download, or email articles for individual use. 